\title{
Loss of function of BRCA1 promotes EMT in mammary tumors through activation of TGF $\beta R 2$ signaling pathway
}

\author{
Feng Bai ${ }^{1,2,3}$, Chuying Wang ${ }^{3,4}$, Xiong Liu ${ }^{1,5}$, Daniel Hollern ${ }^{6}$, Shiqin Liu ${ }^{3,7}$, Cheng Fan ${ }^{6}$, Chang Liu ${ }^{1,5}$, Sijia Ren ${ }^{1,5}$,
} Jason I. Herschkowitz ${ }^{6,9}$, Wei-Guo Zhu ${ }^{8}$ and Xin-Hai Pei $\mathbb{D i D}^{1,3,5} \bowtie$

(c) The Author(s) 2022

BRCA1 deficient breast cancers are aggressive and chemoresistant due, in part, to their enrichment of cancer stem cells that can be generated from carcinoma cells by an epithelial-mesenchymal transition (EMT). We previously discovered that BRCA1 deficiency activates EMT in mammary tumorigenesis. How BRCA1 controls EMT and how to effectively target BRCA1-deficient cancers remain elusive. We analyzed murine and human tumors and identified a role for Tgf $\beta r 2$ in governing the molecular aspects of EMT that occur with Brca1 loss. We utilized CRISPR to delete Tgf $\beta r 2$ and specific inhibitors to block Tgf $\beta r 2$ activity and followed up with the molecular analysis of assays for tumor growth and metastasis. We discovered that heterozygous germline deletion, or epitheliaspecific deletion of Brca1 in mice, activates Tgf $\beta r 2$ signaling pathways in mammary tumors. BRCA1 depletion promotes TGF $\beta$-mediated EMT activation in cancer cells. BRCA1 binds to the TGF $\beta$ R2 locus to repress its transcription. Targeted deletion or pharmaceutical inhibition of Tgf $\beta \mathrm{r} 2$ in Brca1-deficient tumor cells reduces EMT and suppresses tumorigenesis and metastasis. BRCA1 and TGF $\beta R 2$ expression levels are inversely related in human breast cancers. This study reveals for the first time that a targetable TGF $\beta$ R signaling pathway is directly activated by BRCA1-deficiency in the induction of EMT in breast cancer progression.

Cell Death and Disease (2022)13:195; https://doi.org/10.1038/s41419-022-04646-7

\section{INTRODUCTION}

Clinically, breast cancer comprises three main subtypes: human epidermal growth factor receptor 2 (HER2) positive breast cancer, hormone receptor [estrogen receptor (ER) and/or progesterone receptor $(\mathrm{PgR})]$-positive breast cancer, and triple-negative breast cancer (TNBC), the latter of which lacks expression of ER, PgR, and HER2 [1, 2]. Gene-expression analyses have categorized human breast tumor into six intrinsic subtypes: basal-like (BL), claudin-low (CL), Her2-enriched, luminal A, luminal B, and normal breast-like, each of which has unique biological and prognostic features [3]. Of these subtypes of breast cancer, the CL subtype is a TNBC characterized by the high enrichment for epithelial to mesenchymal transition (EMT) markers and cancer stem cell (CSC)-like features [3, 4]. Basal-like breast cancer (BLBC) accounts for approximately $70 \%$ of TNBCs and is a leading cause of cancer deaths worldwide. The high mortality rate of BLBCs can be attributed to the aggressive and metastatic capacity of these tumors and the limited number of effective therapeutic options. BLBCs are highly aggressive and metastatic in part due to their enrichment of CSCs, which are thought to drive clinical relapse and metastasis $[5,6]$. CSCs are more resistant to radio- and chemotherapy and can be generated from carcinoma cells by an
EMT program [7-9], which is a process whereby epithelial cells lose many of their epithelial characteristics and acquire mesenchymal features [9]. While some molecular regulators of EMT have been identified [10], therapeutically targetable mechanisms controlling EMT in BLBCs remain elusive.

TGF $\beta$ signaling plays a key role in inducing and maintaining the mesenchymal and stem cell states of multiple tissues, including breast tissues [11]. TGF $\beta$ ligands bind to their receptors, TGF $\beta R 1 / 2$, which then activate downstream effectors through SMADdependent and SMAD-independent pathways, to activate EMT and drive CSC function $[12,13]$. Further, the expression of TGF $\beta R 2$ is enhanced in ER-negative tumor cells, and is reduced in ER-positive tumor cells [14, 15]. Overexpression of TGF $\beta R 2$ or upregulation of TGF $\beta$ signature genes is associated with lung metastasis and lower survival rates in BLBCs $[16,17]$. Together, these prior studies demonstrate an association between TGF $\beta R 2$ and aggressive tumor phenotypes. Yet, the role of TGF $\beta R 2$ and its status as a putative therapy target in ER-negative BRCA1 deficient tumors is currently unknown.

We and others have reported that BRCA1 deficiency activates p16, p18, and RB, key proteins in controlling cell cycle progression [18-21]. Loss of Brca1 in p16 or p18 deficient mice activates EMT

\footnotetext{
${ }^{1}$ Guangdong Provincial Key Laboratory of Regional Immunity and Diseases, International Cancer Center, Marshall Laboratory of Biomedical Engineering, Shenzhen University Health Science Center, Shenzhen 518060, China. ${ }^{2}$ Department of Pathology, Shenzhen University Health Science Center, Shenzhen 518060, China. ${ }^{3}$ Dewitt Daughtry Family Department of Surgery, University of Miami, Miami, FL 33136, USA. ${ }^{4}$ The Second Affiliated Hospital of Xi'an Jiaotong University, Xi'an, Shaanxi 710061, China. ${ }^{5}$ Department of Anatomy and Histology, Shenzhen University Health Science Center, Shenzhen 518060, China. ${ }^{6}$ Lineberger Comprehensive Cancer Center, University of North Carolina at Chapel Hill, Chapel Hill, NC 27599, USA. ${ }^{7}$ Peking University First Hospital, Beijing 100034, China. ${ }^{8}$ Department of Biochemistry and Molecular Biology, International Cancer Center, Shenzhen University Health Science Center, Shenzhen 518060, China. ${ }^{9}$ Present address: Department of Biomedical Sciences, University at Albany, Rensselaer, NY 12144 , USA.

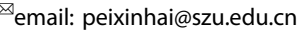
Edited by Dr Satoshi Inoue
}

Received: 4 September 2021 Revised: 25 January 2022 Accepted: 9 February 2022 Published online: 02 March 2022 
and induces BLBCs, whereas, loss of p18 induces luminal type mammary tumors [18-20, 22]. In this study, we follow up on these results to identify the molecular mechanisms by which Brca1 loss promotes EMT.

\section{RESULTS}

Germline deletion of Brca1 activates Tgf $\beta$ signaling and EMT with enhanced expression of $\mathrm{Tgf} \beta \mathrm{r} 2$ in mammary tumor cells We previously demonstrated that heterozygous germline deletion of Brca1 in p18 null mice activated EMT and led to BLBCs with enhanced CSC populations along with the increased potential for metastasis \{Figs. 1A, S1A-C, and details in $[18,19,22]\}$. To identify the molecular determinants for activation of EMT in Brca1 deficient mammary tumors in an unbiased manner, we performed microarray analysis. GSEA revealed enrichment of a signature for active Tgf $\beta$ signaling in $p 18^{-/-} ; B r c a 1^{+/-}$tumors when compared to $p 18^{-\gamma-}$ and $p 18^{+1-}$ tumors (Fig. 1B). Consistent with activation of known downstream pathways by BRCA1 loss [23, 24], signatures for NF-KB pathway activity were also enriched in $\mathrm{p} 18^{-/-} ; \mathrm{BrCa}^{+/-}$ tumors (Fig. S1D). Most (9/10) $p 18^{-/-} ; \mathrm{Brca}^{+/-}$tumors expressed high levels of Tgf $\beta \mathrm{r} 2$, whereas most $(8 / 10) \mathrm{p} 18^{-/-}$and $\mathrm{p} 18^{+/-}$ tumors expressed a low level of Tgf $\beta \mathrm{r} 2$. Analysis of tumors after removal of an outlier $\mathrm{p} 18^{-/-} ; \mathrm{Brca} 1^{+/-}$tumor, a p18 ${ }^{+/-}$tumor and an outlier $\mathrm{p} 18^{-1-}$ sample, revealed that Tgf $\beta \mathrm{r} 2$ mRNA levels in $\mathrm{p} 18^{-/} ; \mathrm{Brca}^{+/-}$tumors were significantly higher than those in p18 ${ }^{-1-}$ tumors (Fig. S2). Interestingly, we found that Tgf $\beta r 2$ mRNA did not elevate in $\mathrm{K} 14-\mathrm{Cre} ; \mathrm{p} 53^{\mathrm{f} / \mathrm{f}} ; \mathrm{Brca}^{\mathrm{f} / \mathrm{f}}$ mammary tumors, suggesting that upregulation of $\operatorname{Tgf} \beta \mathrm{r} 2$ may be unique to Brca1 germline mutant tumors also deficient in p18. We also noted that within individual intrinsic subtypes in genetically engineered mouse models existed a range of expression values for Tgf $\beta r 2$, with statistically significant association of elevated mRNA in $\mathrm{CL}$ subtype (Fig. S2).

We performed IHC and found a significantly enhanced frequency of Tgf $\beta r 2$-positive tumors when $\mathrm{p} 18^{-1-}$; Brca ${ }^{+/-}$ tumors were compared with $p 18^{-/-}$tumors. Furthermore, most $(11 / 12) \mathrm{p}^{18^{-/-}}$; Brca ${ }^{+/-}$tumors with EMT features expressed high levels of Tgf $\beta r 2$ (Fig. 1C, D). Interestingly, we observed an insignificantly increased frequency of $\mathrm{p}^{-8^{-1-}} ; \mathrm{BrCa}^{+/-}$tumors that were Tgf $\beta r 1$-positive when compared with $p 18^{-1-}$ tumors $\left(7 / 14\right.$ positive in $p 18^{-/-} ; \mathrm{Brca}^{+/-}$tumors versus $6 / 14$ positive in $p 18^{-/-}$tumors) (data not shown). Since TGF $\beta$ R2 is also expressed in mammary stromal cells $[12,14]$, we determined the expression of Tgf $\beta \mathrm{r} 2$ and $\mathrm{Ck14}$, an epithelial marker, in tumor cells. We noticed that the majority of $\mathrm{Tgf} \beta \mathrm{r} 2$ positive $\mathrm{p} 18^{-/-} ; \mathrm{BrCa} 1^{+/-}$tumor cells were co-stained with $\mathrm{Ck} 14$, indicative of the epithelium origin of the Tgf $\beta \mathrm{r} 2$ positive tumor cells (Fig. $1 \mathrm{E}$ ). These results imply a possible negative correlation between Brca1 and $\mathrm{Tgf} \beta \mathrm{r} 2$ in mouse mammary tumors.

We examined the expression of Tgf $\beta r 1 / 2$ in mouse embryos in which Tgf $\beta$ signaling and EMT play a critical role in development [9]. The expression of $\operatorname{Tgf} \beta \mathrm{r} 2$, along with a few EMT-inducing transcription factors (EMT-TFs), was significantly increased in p18 ${ }^{-/-} ; \mathrm{BrCa}^{+/-}$embryos relative to their $\mathrm{p} 18^{-1-}$ counterparts. We noted that the expression of Tgf $\beta r 1$ was not different in this same comparison (Fig. S3). Together, our data depicts a clear relationship between Brca1, Tgf $\beta$ 2 , and EMT in our murine system.

\footnotetext{
Specific deletion of Brca1 in mammary epithelia enhances Tgf $\beta \mathrm{r} 2$ expression and activates EMT in mammary tumors We generated $p 18^{-1-} ; \mathrm{Brcal}^{f / f} ;$ MMTV-Cre $\left(p 18^{-1-} ; \mathrm{Brca}^{\text {MGKO}}\right)$ mice, in which Brca1 was specifically deleted in mammary epithelial cells (MECs). $47 \%$ (7/15) of $p 18^{-1-}$ and $73 \%(11 / 15)$ of p18 ${ }^{-/-}$; Brcal ${ }^{M G K O}$ mice developed mammary tumors [19]. Interestingly, we observed lung metastasis in $36 \%(4 / 11)$ of p18 ${ }^{-/-}$; Brca ${ }^{M G K O}$ tumor-bearing mice, but did not observe metastasis in the lungs of mice with $p 18^{-1-}$ tumors. Consistent
}

with prior reports of a linkage between EMT and metastatic potential [25], significantly more $p 18^{-/-} ;$Brcal $1^{M G K O}$ tumors than p18 $8^{-1-}$ tumors were positive for EMT markers including vimentin (Vim), fibronectin (Fn), Twist, and p-Fra1 ddetails in [19]\}. These data demonstrate that specific deletion of Brca1 in p18 null mammary epithelia induces a malignant mammary tumor phenotype with EMT features.

We compared $p 18^{-/-} ;$Brca $1^{M G K O}$ tumors to tumor-free mammary tissues, and to $p 18^{-/-}$tumors. Both Tgf $\beta r 2$ mRNA and protein levels, as well as the level of phosphorylated-Smad2 ( $p$ Smad2), were significantly increased in $p 18^{-/-} ;$Brca $^{\text {MGKO }}$ tumors relative to those in tumor-free mammary tissues of the same mice. In comparison, Tgf $\beta \mathrm{r} 2$ mRNA was moderately enhanced in $p 18^{-/-}$ tumors relative to that in tumor-free mammary tissues of the same mice (Fig. 2A, B). Furthermore, when compared with $p 18^{-1-}$ tumors, most $p 18^{-1-} ; B r c a 1^{M G K O}$ tumors expressed an increased level of Tgf $\beta r 2$ and p-Smad2, as well as p-Akt, p-Erk, and p-Jnk, all of which are Smad-independent downstream effectors activated by Tgf $\beta$-Tgf $\beta \mathrm{r} 2$ signaling (Fig. $2 \mathrm{C}$ ). Immunostaining revealed that Tgf $\beta \mathrm{r} 2$ and $\mathrm{p}$-Smad2 were highly expressed in $p 18^{-/-} ; B r c a 1^{M G K O}$ tumor cells, and that the expression pattern of $\mathrm{Tgf} \beta \mathrm{r} 2$ in $p 18^{-/-}$; Brca $1^{M G K O}$ tumors was similar with the pattern in ${\mathrm{p} 18^{-/}}^{-1} \mathrm{BrCa}^{+I^{-}-}$ tumors (Figs. 1C, E, 2D). When the positive cells were quantified, we found that $\mathrm{H}$ scores for both $\operatorname{Tgf} \beta \mathrm{r} 2$ and $\mathrm{p}$-Smad2 in $\mathrm{p} 18^{-/-}$; Brca $1^{M G K O}$ tumor cells were significantly more than the $\mathrm{H}$ scores in p18 ${ }^{-1-}$ counterparts (Fig. 2E). These data confirm that during mammary tumorigenesis, loss of Brca1 activates Tgf $\beta \mathrm{r} 2$ signaling pathways in an epithelium-autonomous manner.

BRCA1 depletion enhances tumor initiation potential and promotes TGF $\beta$-mediated EMT activation in breast cancer cells We previously reported that CSC-enriched cells were expanded in p18 ${ }^{-1-}$; Brca1 ${ }^{\text {MGKO }}$ mammary tumors relative to their $\mathrm{p} 18^{-/-}$ counterparts [19], and that $\mathrm{p} 18^{-/-} ; \mathrm{Brca1}^{\mathrm{MGKO}}$ tumor cells displayed features that had undergone EMT [26]. We tested the tumor-initiating capacity of tumor cells and found that as low as $1 \times 10^{5}$ of ${\mathrm{p} 18^{-/-}}^{-}$; Brca $1^{\text {MGKO }}$ cells were able to regenerate tumors, whereas as high as $6 \times 10^{6}$ of $\mathrm{p} 18^{-1-}$ cells did not yield tumors. Notably, half of the mammary tumors generated by $6 \times 10^{6} \mathrm{p} 18^{-/-}$; Brca1 ${ }^{\text {MGKO }}$ tumor cells metastasized to the lung (Fig. 2F)' Furthermore, we detected significantly more primary tumorspheres formed by $\mathrm{p} 18^{-1-}$; Brca $1^{\text {MGKO }}$ tumor cells than those done by p18 ${ }^{-1-}$ tumor cells (Fig. 2G). Together, these illustrate that loss of Brca1 in breast cancer cells enhances the CSC population and its property in tumor initiation.

To test if Tgf $\beta r 2$ activation promotes EMT in Brca1 deficient tumor cells, we used a TGF $\beta$ challenge assay. We confirmed the increase of $\mathrm{Tgf} \beta \mathrm{r} 2$ expression in $\mathrm{p} 18^{-1-} ; \mathrm{Brca1}^{\mathrm{MGKO}}$ tumor cells relative to that in $\mathrm{p} 18^{-/-}$cells (Fig. $3 \mathrm{~A}$ ). In $\mathrm{p} 18^{-/-}$cells, TGF $\beta$ treatment resulted in modest changes in EMT marker genes (increase of mesenchymal and decrease of epithelial genes), which was likely due to the diminished Tgf $\beta \mathrm{r} 2$ expression observed in these tumor cells. However, in $\mathrm{p}^{-18^{-1}} ; \mathrm{Brca}^{\mathrm{MGKO}}$ cells, the dramatic elevation of EMT markers was noted (Figs. 3B, S4A). We then knocked down BRCA1 in MCF7, T47D, and MDA-MB-231 cell lines, all of which are BRCA1 wild type (Wt) [19]. We discovered that the depletion of BRCA1 stimulated the expression of TGF $\beta R 2$ mRNA. In response to TGF $\beta$ treatment, BRCA1-depleted cells, but not control cells, expressed a distinctly lower level of epithelial markers (CDH1, CK8) and higher level of mesenchymal markers (PDGFR $\beta$, VIM), as well as EMT-TFs including FOSL1 (encoding FRA1), TWIST, and SNAIL (Figs. 3C-F, S4B, C). These results indicate that BRCA1 deficiency in cancer cells stimulates TGF $\beta$ R2 expression and promotes TGF $\beta$-mediated EMT activation.

\section{BRCA1 suppresses transcription of TGF $\beta R 2$}

We transfected BRCA1 into BRCA1-mutant cell lines, HCC1937 and SUM149, respectively. The introduction of functional BRCA1 led to 
A

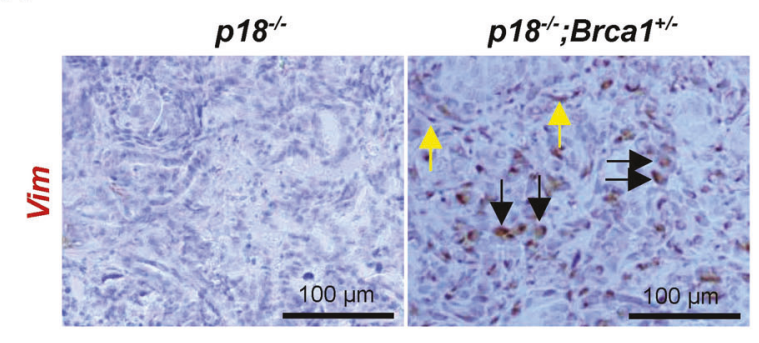

B

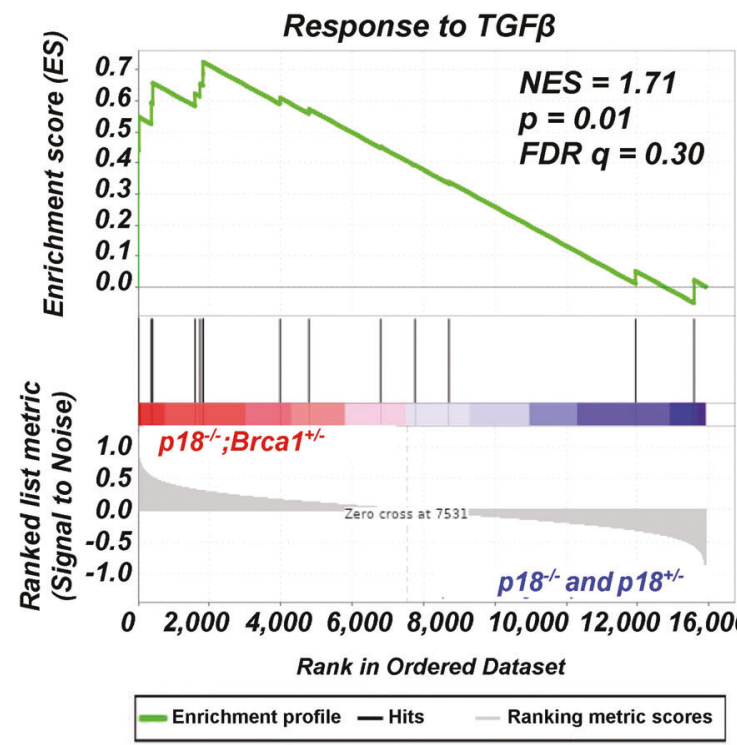

C

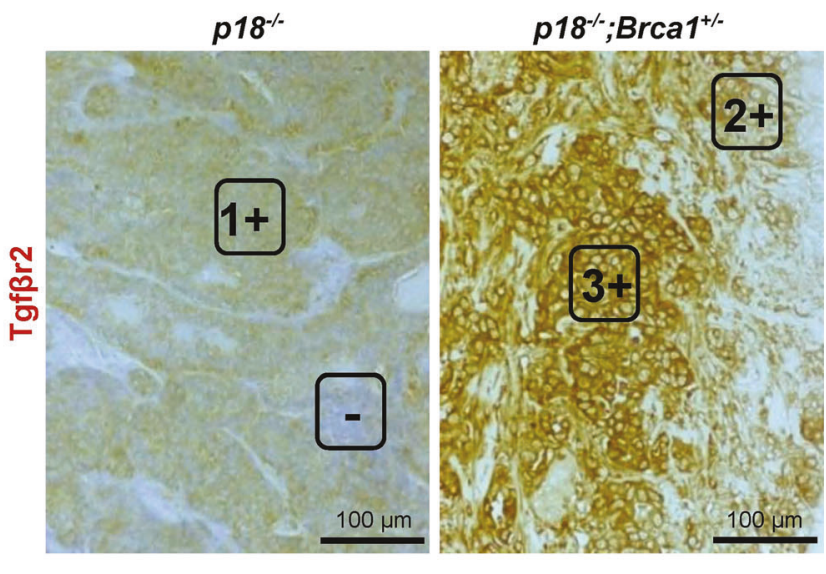

D

\begin{tabular}{|l|l|l|}
\hline Genotype & p18 & p1- \\
\hline Mammary Tumor & $20 / 25(80 \%)$ & $17 / 21(81 \%)$ \\
\hline EMT+ Tumor & $4 / 20(20 \%)$ & $12 / 17(71 \%)^{*}$ \\
\hline Tgf $\beta r 2+$ tumor & $5 / 20(25 \%)$ & $11 / 17(65 \%)^{*}$ \\
\hline
\end{tabular}

E
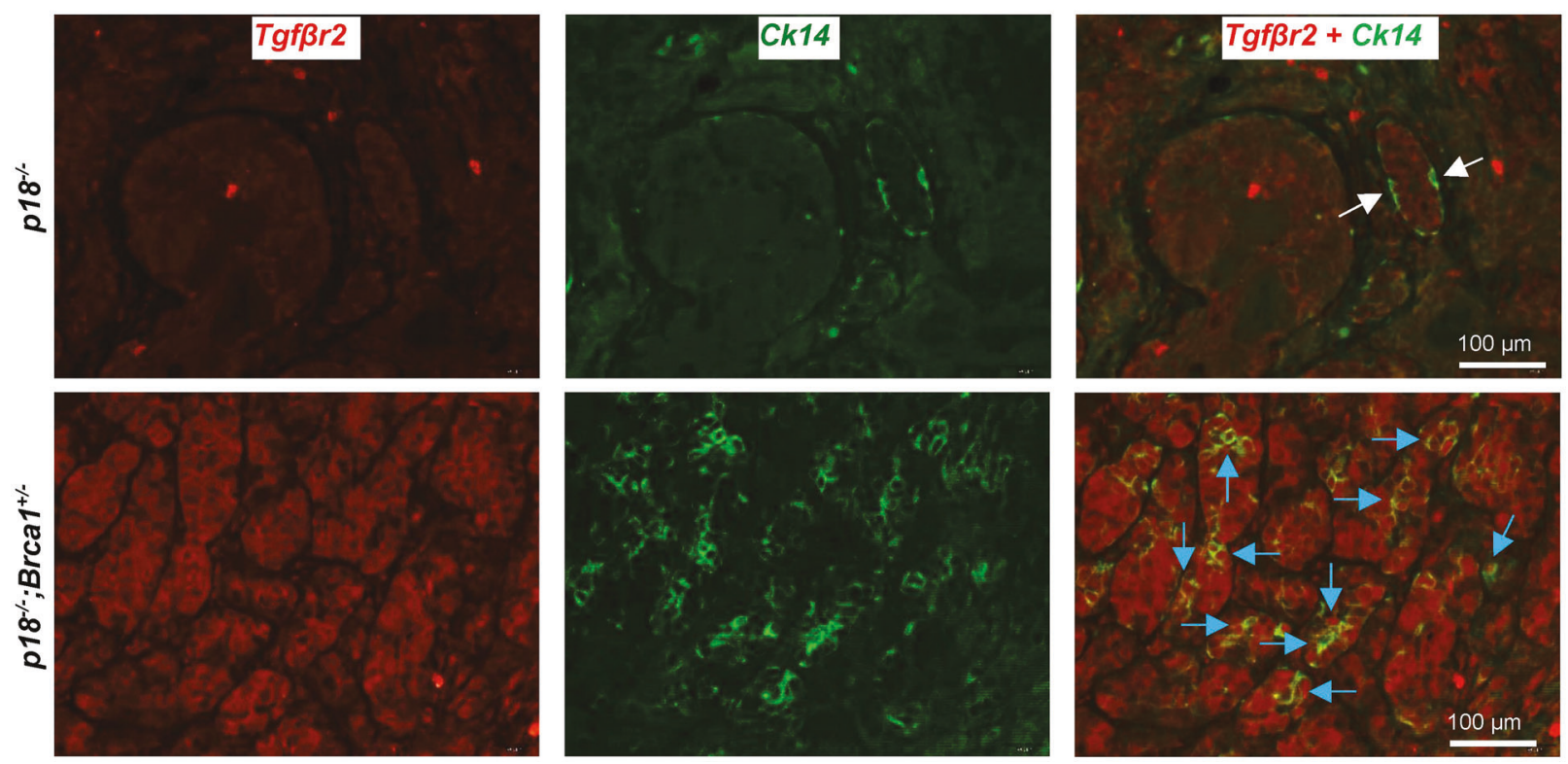

lower mRNA and protein levels of TGF $\beta$ R2. Consistent with our previous finding [19], overexpression of BRCA1 resulted in a decrease of mesenchymal markers and EMT-TFs (Figs. 4A, S5). These data confirm that BRCA1 represses the expression of TGF $\beta R 2$ and inhibits EMT.

We and others have shown that GATA3 recruits BRCA1 to its binding sites in the promoters of FOXC $1 / 2$ and TWIST genes to repress their transcription $[19,27]$. Analysis of the TGF $\beta R 2$ locus revealed at least twelve putative BRCA1/GATA3 binding sites (Fig. 4B). We performed ChIP assays using 8 pairs of primers that cover all twelve putative BRCA1/GATA3 binding sites. Six out of eight amplicons (P1, P2, P4, P5, P7, and P8) in T47D cells and three out of eight amplicons (P1, P2, and P5) in HCC1937 cells transfected with BRCA1 were specifically enriched in the 
Fig. 1 Heterozygous germline deletion of Brca1 in p18 deficient mice activates EMT and Tgf $\beta$ signaling with an increase of Tgf $\beta r 2$ expression in mammary tumor cells. A Representative IHC analysis of mammary tumors with antibodies against Vim. Vim positive tumor cells (Black arrows) and stromal cells (Yellow arrows) are indicated. B Microarray analysis of mammary tumors. GSEA enrichment plot for a signature for Tgf $\beta$ signaling activity. NES: Normalized Enrichment Score (NES), Nominal $p$ value $(p)$, and False Discovery Rate $q$-value (FDR $q$ ) were detected comparing $p 18^{-/-} ; \operatorname{Brca} 1^{+/-}$tumors $(n=10)$ to $p 18^{-/-}$and $p 18^{+/-}$tumors including nine $p 18^{-1-}$ and one $p 18^{+/-}$tumors. C Representative IHC analysis of mammary tumors from a $p 18^{-/-}$and $p 18^{-/-}$; Brca $1^{+/-}$mice. To quantify the Tgf $\beta \mathrm{r} 2$ positive tumor cells, the intensity of Tgf $\beta \mathrm{r} 2$ antibody-specific staining by IHC in tumor cells were categorized into -, $1+, 2+$, and $3+$. The representative images in the boxed area for each category were shown. D Summary of mammary tumors in mice with Balb/c background. EMT + tumors are tumors that are positive for at least two EMT markers (decreased E-Cad, increased Vim, Fn1, or CD29), and two EMT-TFs (Twist, Snail, Slug, Foxc2 or pFra 1$)$ in $>2 \%$ tumor cells. Tgf $\beta r 2+$ tumors are tumors that are positive for Tgf $\beta r 2$ with $2+$ or $3+$ intensity in $>20 \%$ tumor cells. The asterisk $(*)$ denotes a significance from $\mathrm{p} 18^{-/-} ; \mathrm{Brca}^{+/-}$and $\mathrm{p} 18^{-/-}$tumors by two-tailed Fisher's exact test. E Representative immunofluorescent staining of mammary tumors from a $p 18^{-/-}$and $p 18^{-/-} ; B r c a 1^{+/-}$mice. Note that the majority of Tgf $\beta r 2$ positive $p 18^{-/-} ; B r c a 1^{+/-}$tumor cells were co-stained with Ck14 (blue arrows). Ck14 singly positive basal epithelial cells (white arrows) in the normal gland are indicated.

A

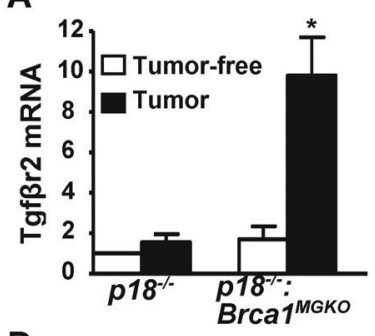

D

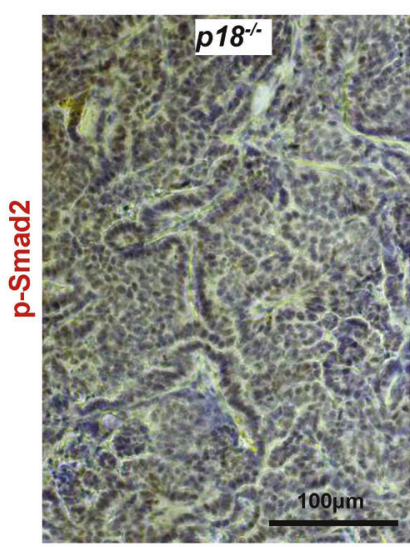

B
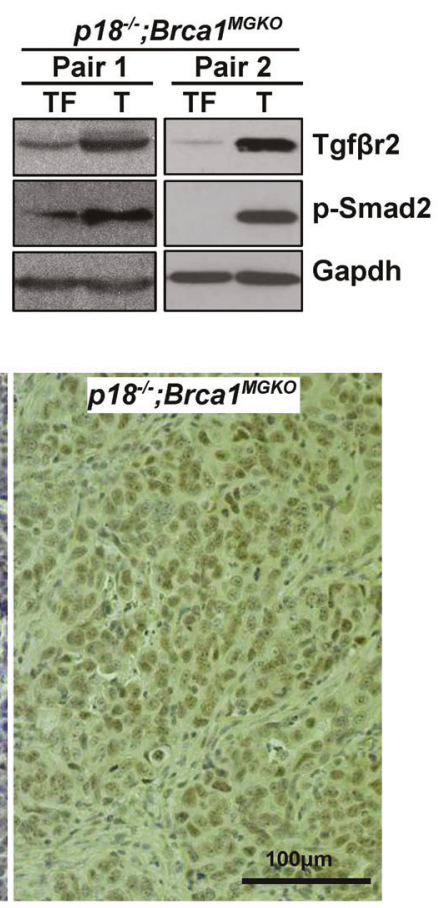

C

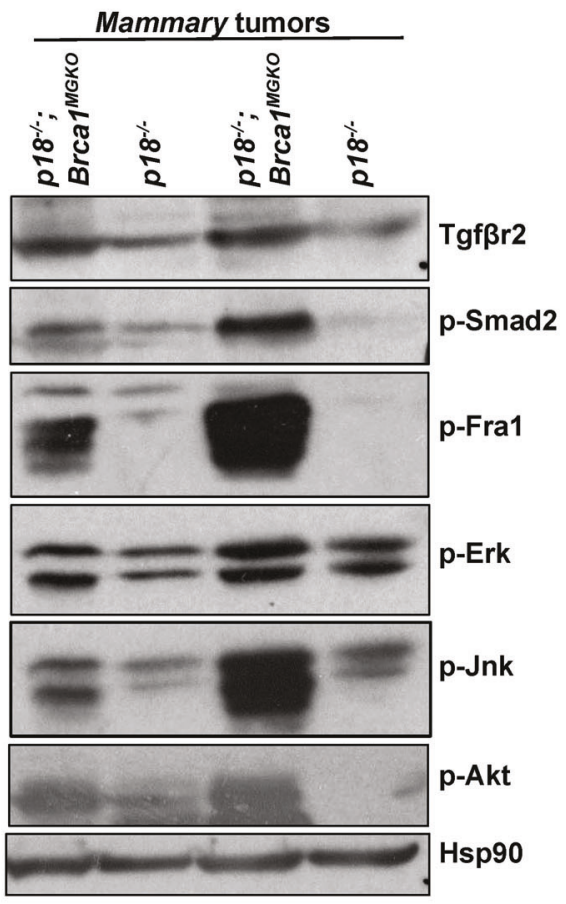

G
E

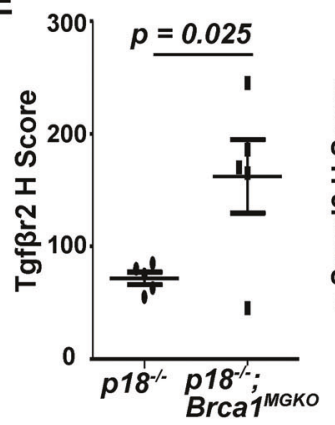

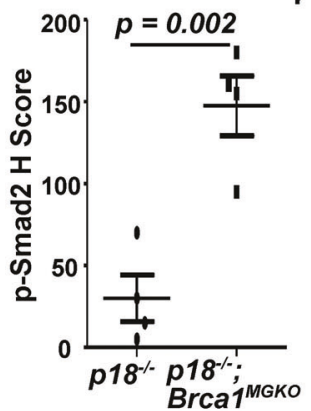

$\mathbf{F}$

\begin{tabular}{|l|l|l|}
\hline Genotype & $\begin{array}{l}\text { \# of cells } \\
\text { injected }\end{array}$ & $\begin{array}{l}\text { Tumor } \\
\text { incidence }\end{array}$ \\
\hline$p 18^{-/ *}$ & $6 \times 10^{6}$ & $0 / 10$ \\
\hline $\begin{array}{l}\text { p18 }{ }^{-/ ;} ; \\
\text {Brca } 1^{\text {MGKo }}\end{array}$ & $6 \times 10^{6}$ & $10 / 10^{\#}$ \\
\cline { 2 - 3 } & $6 \times 10^{5}$ & $10 / 10$ \\
\cline { 2 - 3 } & $1 \times 10^{5}$ & $4 / 4$ \\
\hline
\end{tabular}

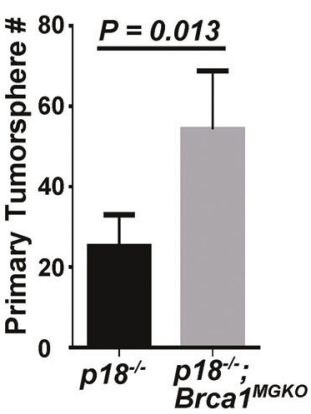

Fig. 2 Deletion of Brca1 in p18 ${ }^{-/-}$epithelia activates Tgf $\beta r 2$ signaling pathways and promotes tumor-initiating potential. A, B Tumors ( $T$ ) from $p 18^{-/-}$and $p 18^{-1-} ; B r c a 1^{\text {MGKO }}$ mice were analyzed by qRT-PCR (A) and western blot (B). Tumor-free mammary glands (TF) from the same mouse were used as controls. Data in (A) represent the mean \pm SD of three tumors in each group. The asterisk $(*)$ denotes a significance from tumors and tumor-free tissues of the same genotype by a two-tailed, unpaired $T$ test. C Four representative tumors from $p 18^{-/-}$and $p 18^{-/-}$; Brca ${ }^{\text {MGKO }}$ mice were analyzed by western blot. D Representative immunostaining of mammary tumors from a $p 18^{-/-}$and $p 18^{-1-} ; B r c a 1^{\text {MGKÓ }}$ mice. E $p 18^{-1-}$ and $p 18^{-1-}$;Brca $1^{\text {MGKO }}$ mammary tumors were analyzed by IHC, and H-scores for Tgf $\beta \mathrm{r} 2$ and $\mathrm{p}$-Smad 2 were calculated. The results represent the mean \pm SD of five individual tumors per group for Tgf $\beta r 2$ and four individual tumors per group for $p$-Smad2. $F$ p18 ${ }^{-/-}$ and $p 18^{-1-} ; B r c a 1^{\text {MGKO }}$ mammary tumor cells were transplanted into MFPs of NSG mice. Four weeks later, recipient mice with tumors generated $\left(>0.5 \mathrm{~cm}^{3}\right.$ in size) were analyzed. "\#ive tumor-bearing mice displayed lung metastasis by H.E. analysis. G $3 \times 10^{4} p 18^{-1-}$ and $p 18^{-1-}$; Brca $1^{\text {MGKO }}$ mammary tumor cells were cultured to generate primary tumorspheres in 10 days. The number of spheres large than 50 um was quantified from triplicate experiments. The results represent the mean \pm SD of three individual tumors per group. Statistical significance in (E) and $(\mathbf{G})$ was determined by a two-tailed, unpaired $T$ test. 
A

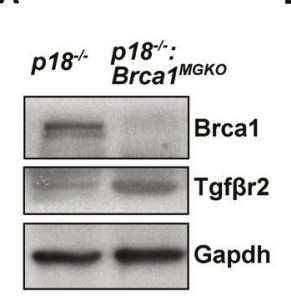

C

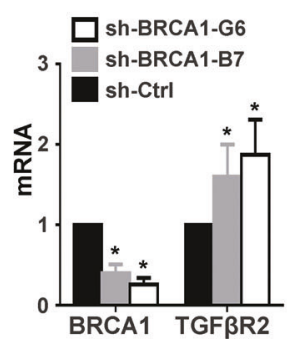

D
B

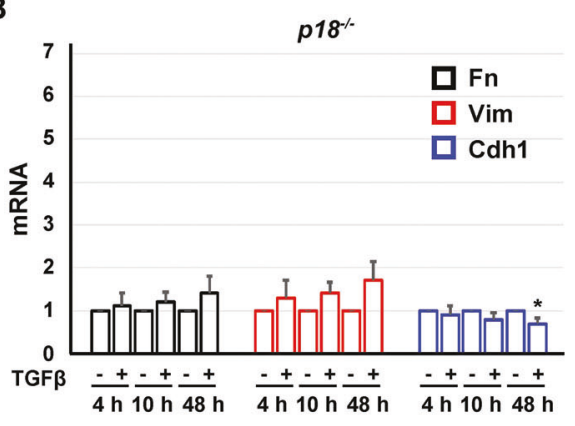

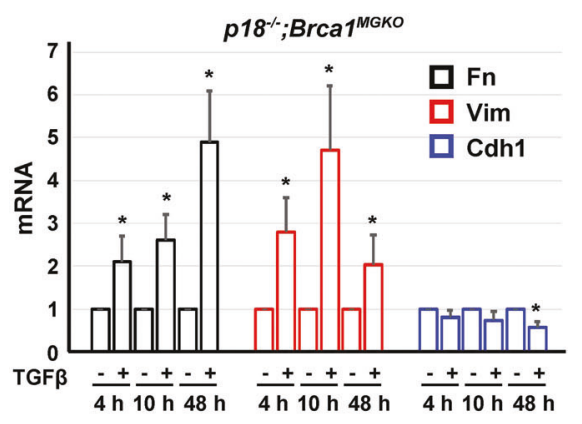

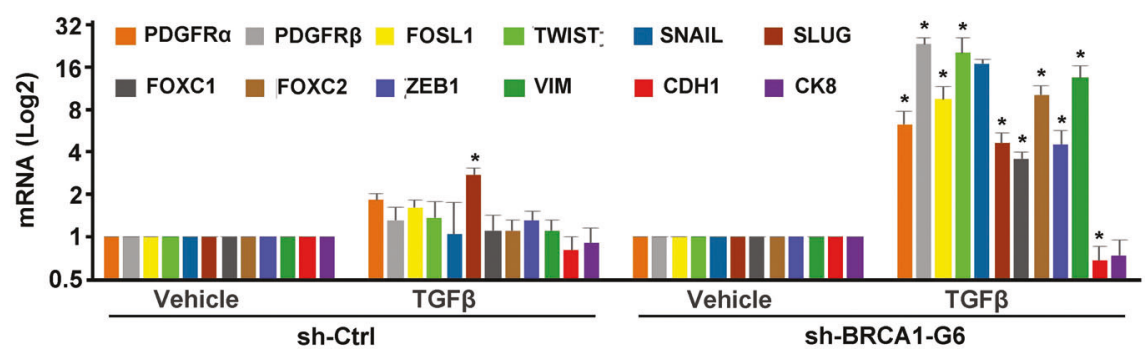

E

$\mathbf{F}$
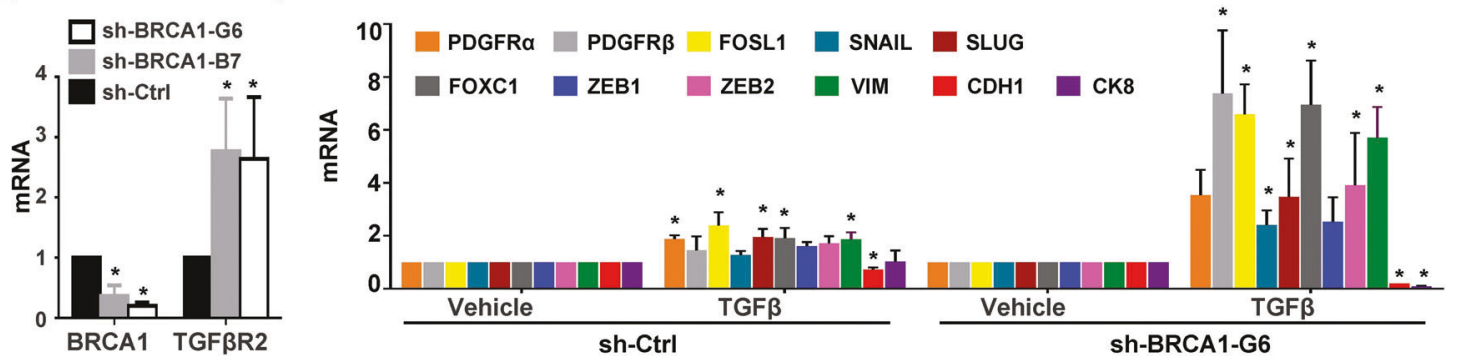

Fig. 3 BRCA1 depletion sensitizes tumor cells to TGF $\beta$-mediated EMT activation. A, B Representative $p 18^{-/-}$and $p 18^{-/-}$; Brca $1^{\mathrm{MGKO}}$ mammary tumor cells were analyzed by western blot (A) or treated with vehicle or TGF $\beta$ for different time periods, and then analyzed by qRTPCR (B). Data in (B) represent the mean \pm SD from duplicates of two independent experiments from two different pairs of primary tumor cell lines. C, E MCF7 (C) and MDA-MB-231 (E) cells were infected with either pGIPZ-empty (sh-Ctrl.) or pGIPZ-shBRCA1 targeting different sequences of human BRCA1 (sh-BRCA1-B7 and sh-BRCA1-G6). Cells stably expressing sh-Ctrl or shBRCA1 were analyzed by qRT-PCR. Data represent the mean \pm SD from triplicates of each of the two independent experiments. D, F mRNA levels in MCF7-sh-Ctrl and MCF7-sh-BRCA1G6 (D), or MDA-MB-231-sh-Ctrl and MDA-MB-231-sh-BRCA1-G6 (F) cells treated with TGF $\beta$ for 10 (D) or 24 (F) hours were analyzed. Data represent the mean \pm SD from duplicates of two independent experiments. The asterisk $\left(^{*}\right)$ in $(\mathbf{B})(\mathbf{D})$ and $(\mathbf{F})$ denotes a statistical significance from vehicle- and TGF $\beta$-treated samples determined by a two-tailed, paired $T$ test. The asterisk $\left(^{*}\right)$ in $(\mathbf{C})$ and $(\mathbf{E})$ denotes a statistical significance from sh-BRCA1 and sh-Ctrl samples determined by a two-tailed, paired $T$ test.

immunoprecipitation of BRCA1 (Fig. 4C, D). Together with the experimental evidence that BRCA1 represses TGF $\beta R 2$, we attribute these observations to direct repression by the binding of BRCA1 to the TGF $\beta R 2$ locus.

We generated TGF $\beta$ R2 promoter-luciferase fusion plasmids, pGL3-TGF $\beta R 2$-WT containing a promoter region that covers P5 amplicon, and pGL3-TGF $3 R 2-$ Mut in which a BRCA1/GATA3 binding site of pGL3-TGF $\beta$ R2-WT was mutated (Fig. 4E). We transfected the plasmids into SUM149 cells and found that relative to an empty control; ectopic BRCA1 drastically reduced the activity of pGL3-TGF $\beta$ R2-WT promoter by $\sim 60 \%$. On the other hand, the transfection slightly reduced the activity of pGL3-TGFßR2-Mut promoter by $\sim 18 \%$ (Fig. 4F, left). Furthermore, we detected that the activity of pGL3-TGF $\beta$ R2-WT promoter was significantly increased in T47D-sh-BRCA1 cells relative to their T47D-sh-Ctrl cell counterparts. However, this was not the case when we examined the activity of pGL3TGF $\beta R 2-M u t$ promoter (Fig. 4F, right). These data reaffirm our conclusion that BRCA1 binds to BRCA1/GATA3 sites in TGF $\beta R 2$ promoter to suppress its activity.
Targeted deletion of Tgf $\beta \mathrm{r} 2$ in Brca 1 deficient tumor cells suppresses EMT and inhibits tumor initiation and metastasis We knocked out Tgf $\beta r 2$ in $p 18^{-/-} ; B r c a 1^{M G K O}$ tumor cells and found that Tgf $\beta \mathrm{r} 2 \mathrm{KO}$ led to lower expression of the EMT markers Vim, Fn, Snail, Zeb1, Slug, and higher expression of the epithelial markers including Cdh1 and Epcam (Fig. 5A, B). Morphologically, Tgf $\beta r 2-d e p l e t e d$ tumor cells exhibited more epithelial-like phenotypes including islets of cells with close cell-cell contacts and cobblestone morphology, but less mesenchymal-like phenotypes including a reduction in spindle-shaped cells (Fig. 5C). We then treated cells with TGF $\beta$, and found that in response to the treatment the elevation of $\mathrm{Fn}$ and Vim in control-depleted cells was drastically reduced in Tgf $\beta \mathrm{r} 2$-depleted cells (Figs. 5D, S6A). These results indicate that depletion of $\mathrm{Tgf} \beta \mathrm{r} 2$ in $\mathrm{p} 18^{-1-}$; Brcal $^{M G K O}$ tumor cells inhibits EMT in vitro.

We transplanted tumor cells into mice. Though all four mice received $6 \times 10^{5} \mathrm{Tgf} \beta \mathrm{r} 2$ - and control-depleted $p 18^{-/-} ; \mathrm{Brca} 1^{M G K O}$ tumor cells developed tumors, tumors generated by Tgf $\beta \mathrm{r} 2-$ knockout cells were significantly smaller than tumors generated by control cells (Fig. 5E). Tumors generated by Tgf $\beta r 2$-depleted cells 
A

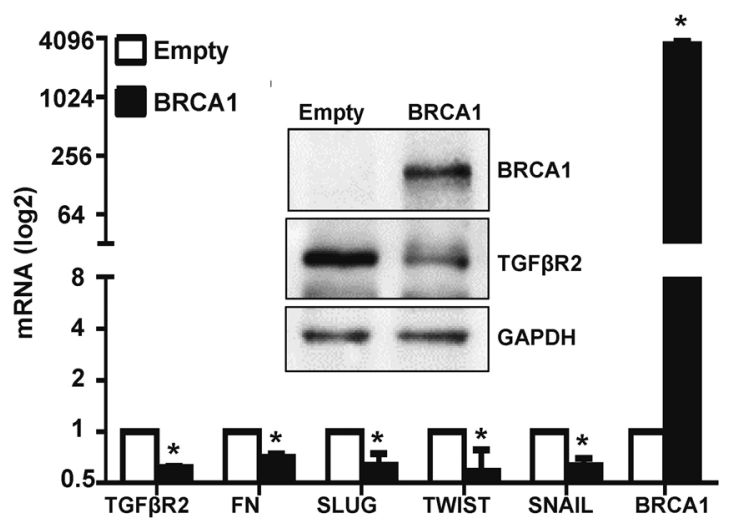

B

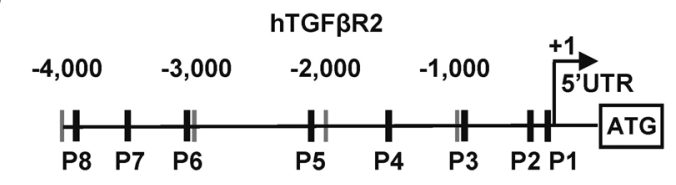

C

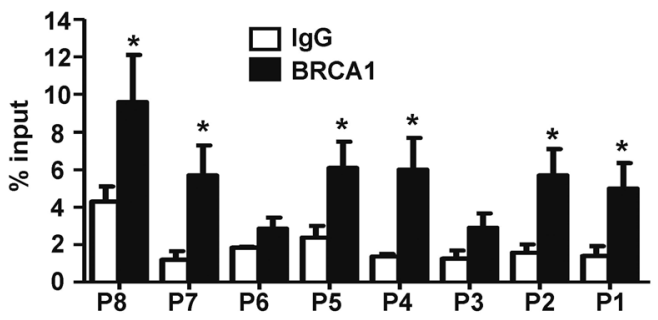

D

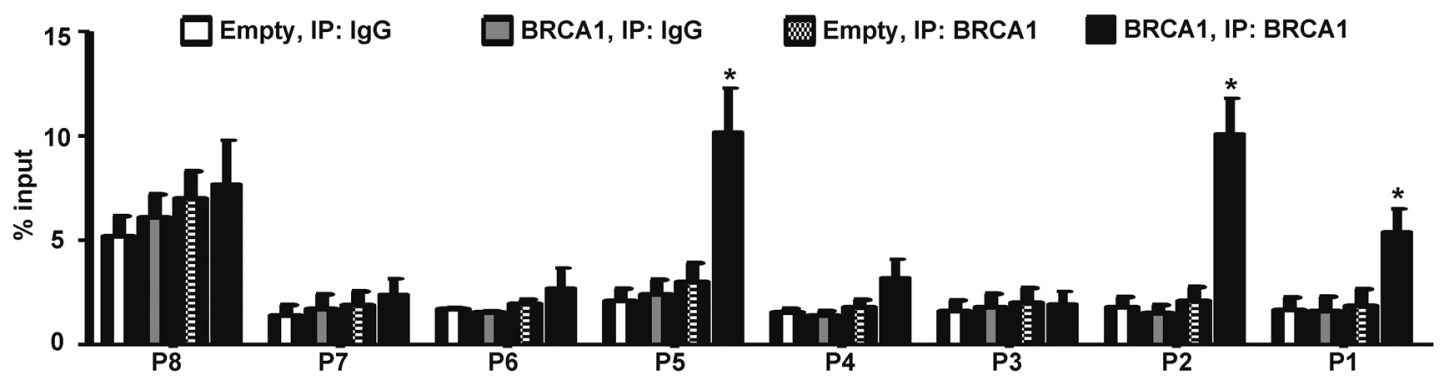

$\mathbf{E}$

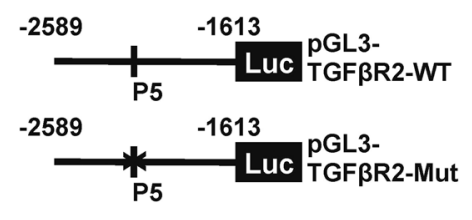

$\mathbf{F}$

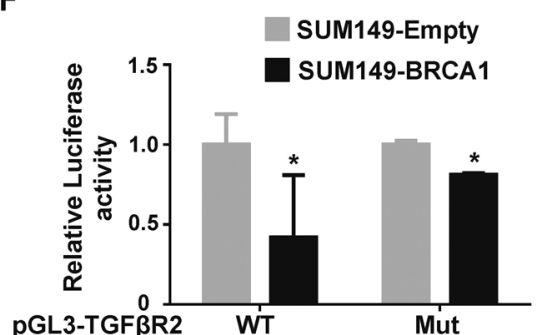

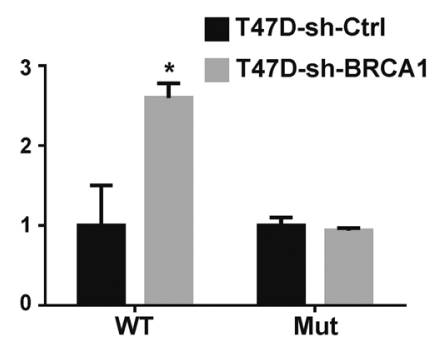

Fig. 4 BRCA1 binds to TGF $\beta$ R2 locus and represses expression of TGF $\beta$ R2 and EMT-associated genes. A SUM149 cells were transfected with pBabe-empty (Empty) or pBabe-HA-BRCA1 (BRCA1). The expression of genes indicated was determined by western blot and/or qRT-PCR $72 \mathrm{~h}$ after transfection. Data represent the mean \pm SD from triplicates of two independent experiments. The asterisk $(*)$ denotes a statistical significance from empty- and BRCA1-expressing samples determined by a two-tailed, paired T test. B Diagram showing the location of putative BRCA1 binding sites (dark black bars) in the human TGF $\beta$ R2 gene, and that of primers (P1 - P8) used for ChIP analysis. + 1 , transcription start site. C ChIP analysis of endogenous BRCA1 binding to putative BRCA1 sites on the TGF $\beta R 2$ locus in T47D cells. Normal IgG was used as a negative control. The ratio of binding signal to input was compared. Data represent the mean \pm SD from triplicates of two independent experiments. The asterisk $\left(^{*}\right)$ denotes a statistical significance from IgG and anti-BRCA1 immunoprecipitated samples by a twotailed, unpaired T test. D ChIP analysis of exogenous BRCA1 binding to the TGF $\beta$ R2 locus in HCC1937 cells transfected with pBabe-empty (Empty) or pBabe-HA-BRCA1 (BRCA1). Normal lgG was used as a negative control. The ratio of binding signal to input was compared. Data represent the mean \pm SD from triplicates of two independent experiments. The asterisk $\left(^{*}\right)$ denotes a statistical significance from Empty- and BRCA1-expressing samples immunoprecipitated by anti-BRCA1 by a two-tailed, unpaired T test. E A schematic representation of WT and Mut TGF $\beta$ R2 promoter-reporter constructs. Numbers represent a position relative to the transcription start site and a letter (X) denotes a mutated GATA3 binding site. The location of primers used for ChIP analysis is shown. F T47D-sh-Ctrl and T47D-sh-BRCA1 cells were transfected with Renilla and pGL3-TGF $\beta$ R2-WT or pGL3-TGF $\beta$ R2-Mut (right panel), and SUM149 cells were transfected with Renilla and pGL3-TGF $\beta$ R2-WT or pGL3-TGF $\beta R 2-M u t$, as well as pBabe-empty or pBabe-HA-BRCA1 (left panel), which were then collected after $48 \mathrm{~h}$ and assayed for luciferase activity. Data represent the mean \pm SD from triplicates of two independent experiments. The asterisk $(*)$ denotes a statistical significance from BRCA1 and empty (left panel), or sh-BRCA1 and sh-Ctrl (right panel) samples determined by a two-tailed, paired $T$ test. SUM149, BRCA1 mutant (Mut); T47D, BRCA1 wild type (Wt).

expressed noticeably reduced levels of Vim and p-Fra1 when compared with tumors generated by control cells (Figs. 5F, S6B). These results demonstrate that the deletion of Tgf $\beta r 2$ in Brca1deficient tumor cells inhibits EMT and suppresses tumorigenesis.

We also discovered that mammary tumors generated by Tgfbr2 $\mathrm{KO}$ cells produced significantly less metastatic nodules in the lung when compared with the tumors initiated by control cells (Fig. 5G-I). These results indicate that the deletion of $\mathrm{Tgf} \beta \mathrm{r} 2$ inhibits the metastatic potential of Brca1 deficient mammary tumor cells.
Inhibition of Tgf $\beta$ r2 in Brca1 deficient tumor cells suppresses EMT and tumor initiation

We treated $p 18^{-1-} ; B r c a 1^{M G K O}$ tumor cells with a TGF $\beta R 2$ inhibitor ITD1, which specifically enhances degradation of Tgf $\beta r 2$ [28]. We confirmed that ITD1 treatment reduced the level of Tgf $\beta r 2$ and its downstream effector protein p-Smad2 (Fig. 6A). ITD1 treatment of the cells from primary $p 18^{-\prime-} ; B r c a 1^{M G K O}$ tumorspheres significantly reduced secondary tumorsphere formation (Fig. 6B). We transplanted tumorsphere-dissociated cells that were pretreated with 
A

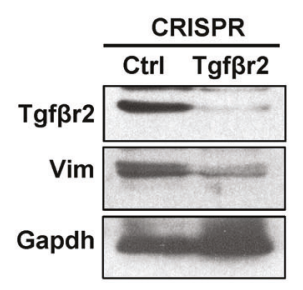

C
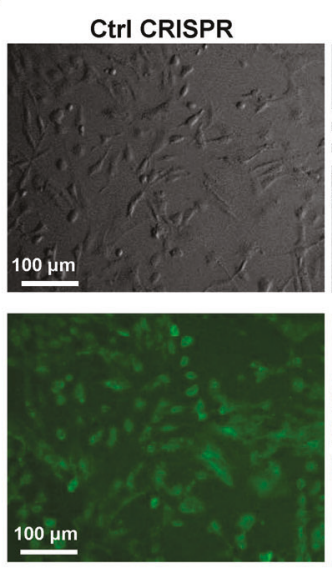

G

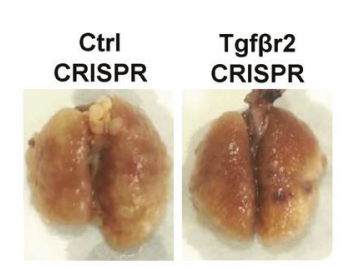

B

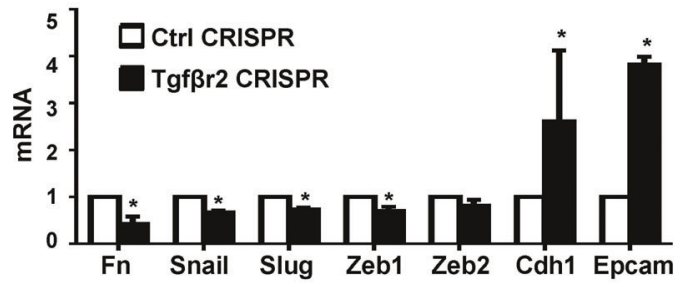

D

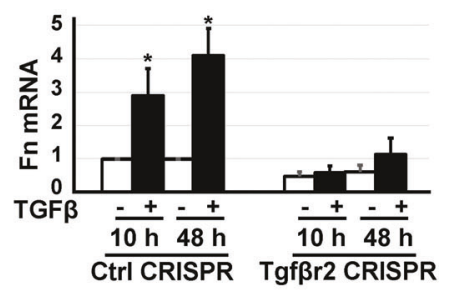

$\mathbf{E}$
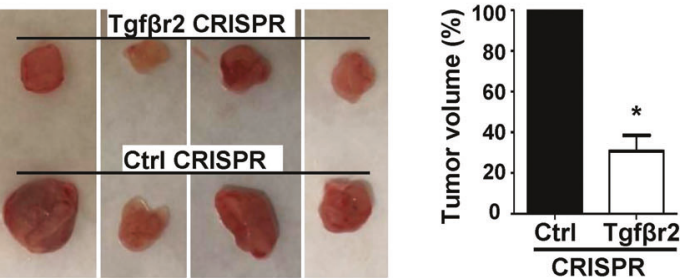

$\mathbf{F}$

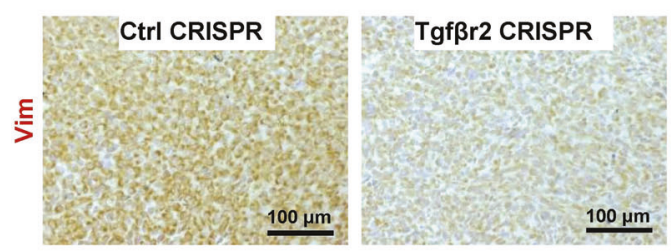

H

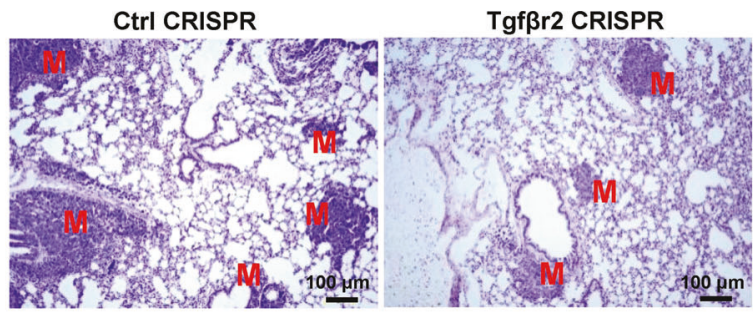

I

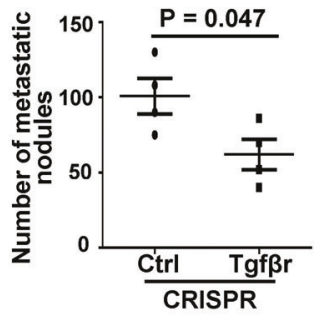

Fig. 5 Deletion of Tgf $\beta \mathbf{r} 2$ in Brca1-deficient tumor cells inhibits EMT and suppresses tumorigenesis and metastasis. A-C $p 18^{-/-} ; B r c a 1^{\mathrm{MGKO}}$ tumor cells were transfected with Tgf $\beta \mathrm{r} 2$ (Tgf $\beta \mathrm{r} 2$ CRISPR) and Control (Ctrl CRISPR) Double Nickase plasmids then selected with puromycin for 3 days. Tgf $\beta$ r2- and control-knockout cells were then analyzed by western blot (A), Q-RT-PCR (B), and microscope for cell morphology (C). The areas with epithelial-like cells are indicated in (C). D Tgf $\beta r 2-$ and Ctrl-knockout $p 18^{-1-}$; Brca ${ }^{\text {MGKO }}$ mammary tumor cells were treated with vehicle or TGF $\beta$ for different time periods, and the expression of Fn was then determined. Data in (B) and (D) represent the mean \pm SD from duplicates of two independent experiments. The asterisk $\left(^{*}\right)$ in $(\mathbf{B})$ denotes a statistical significance from Tgf $\beta \mathrm{r} 2-$ and Ctrl-knockout samples, and in (D) denotes a statistical significance from TGF $\beta$ treated and vehicle treated samples determined by a two-tailed, paired $T$ test. E, $\mathbf{F}$ $6 \times 10^{5} \mathrm{Tgf} \beta \mathrm{r} 2$ - and Ctrl-knockout $p 18^{-/-} ; B_{10 a} 1^{\text {MGKO }}$ mammary tumor cells were inoculated into the left and right inguinal MFPs of NSG mice, respectively, in a pairwise manner. Two weeks after transplantation, mice were dissected. The volume (E) and expression of Vim (F) of the regenerated tumors were determined by measurement and IHC. Data in (E) represent the mean \pm SD of four tumors in each group. The asterisks $\left({ }^{*}\right)$ denote a statistical significance from Tgf $\beta r 2$ - and Ctrl-knockout tumors determined by a two-tailed, paired $T$ test. G-I $6 \times 10^{5}$ Tgf $\beta$ r2- or Ctrl-knockout $p 18^{-1-}$; Brca $1^{\text {MGKO }}$ mammary tumor cells were inoculated into the MFPs of NSG mice. When newly generated tumors reached the maximum size allowed by IACUC in 4-7 weeks, or the mice became moribund, lungs were examined for gross appearance (G), H.E. staining $(\mathbf{H})$, and quantification of the number of metastatic nodules (I). M, metastatic nodules. Data in (I) represent the mean \pm SD for the numbers of metastatic nodules detected in all lobes of the lungs in each group $(n=4)$. Statistical significance was determined by a two-tailed, unpaired $T$ test.

ITD1 into mice. Pretreatment of $p 18^{-/-} ; B r c a 1^{M G K O}$ tumorspheredissociated cells with ITD1 led to significantly smaller tumors than those with vehicle pretreatment (Fig. 6C). Analysis of the newly generated tumors revealed that relative to control tumors, ITD1 tumors exhibited less Tgf $\beta \mathrm{r} 2$, p-Smad2, and EMT-TFs including Twist and Snail, but more E-Cad (Fig. 6D, E). These data suggest that pharmaceutical inhibition of Tgf $\beta r 2$ in Brca1-deficient tumor cells suppresses EMT and their potential for tumor initiation.

\section{$B R C A 1$ and TGF $\beta R 2$ expression levels are inversely related in} human breast cancers

Prompted by these observations in mouse models and prior studies showing enhanced expression of TGF $\beta$ R2 in CSC-enriched
BLBC cells $[14,15]$, we examined the relationship between BRCA1 with TGF $\beta R 2$ mRNA levels in human breast cancer sample sets $[3,29,30]$. Just as in our mouse model, we observed a significantly inverse relationship between BRCA1 and TGF $\beta R 2$, and a less significantly inverse relationship between BRCA1 and TGF $\beta R 1$ (Figs. 7A, S7B). Consistent with our observations in mouse models, human $\mathrm{CL}$ tumors show low BRCA1 mRNA and higher TGF $\beta R 2$ mRNA levels (Figs. 7B, S7A).

To test if these observations are consistent at the protein level we turned to our previously published resource of 43 invasive breast cancers [19]. We found that TGF $\beta$ R2 H scores were significantly higher in ER-negative than ER-positive tumors, while BRCA1 mRNA was lower in ER-negative tumors. 
A

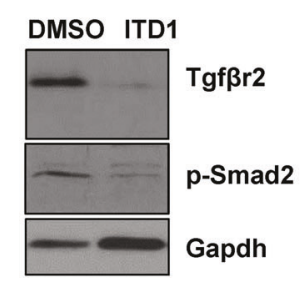

E

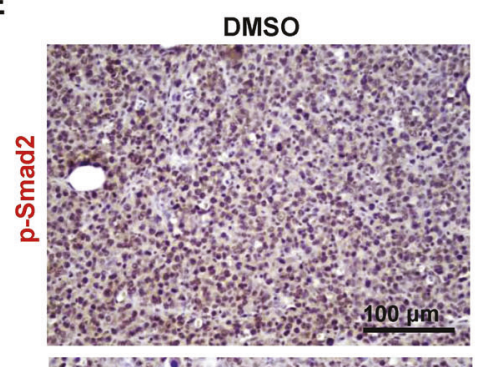

B

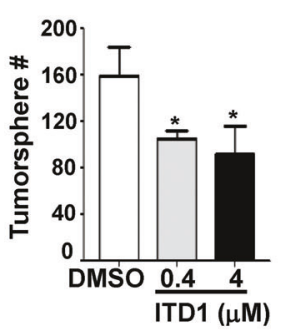

C

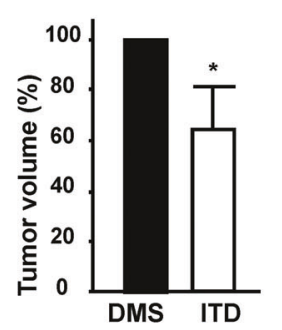

D

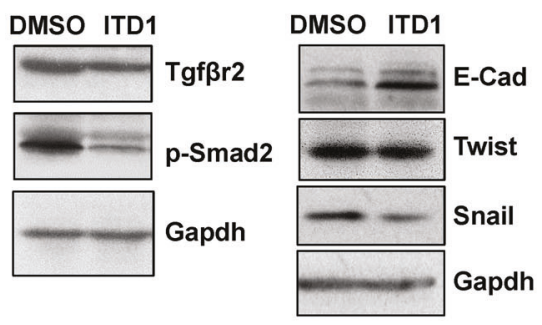

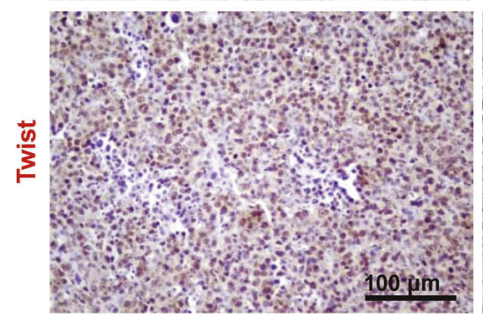
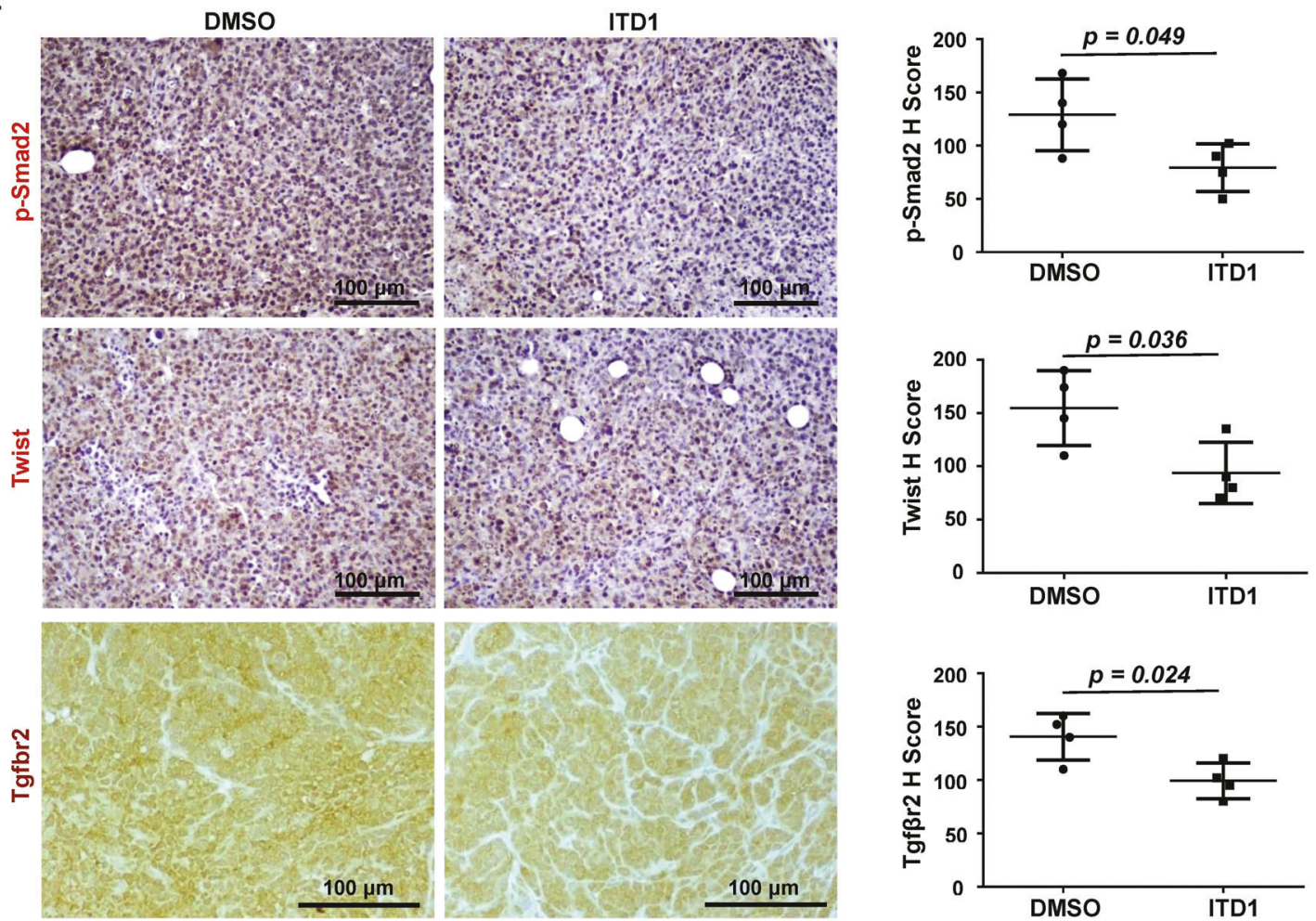

Fig. 6 Pharmaceutical inhibition of Tgf $\beta \mathrm{r} 2$ in Brca1 deficient tumor cells suppresses EMT, tumorsphere formation, and tumor initiation. A $18^{-/-}$; Brca $1^{M G K O}$ tumor cells treated with ITD 1 at $4 \mu \mathrm{m}$ for $24 \mathrm{~h}$ were analyzed by western blot. B $10^{4}$ cells dissociated from $18^{-/-}$; Brca $1^{M G K O}$ primary tumorspheres were treated with ITD1. Secondary spheres formed after 6 days of treatment were counted from quadruplicate

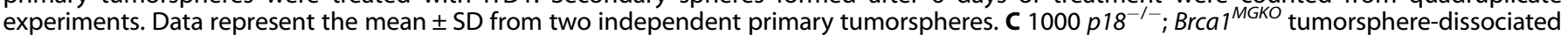
cells pretreated with DMSO or ITD1 for 6 days were transplanted into MFPs of NSG mice. Four weeks later, mice were dissected and tumor volumes were measured. Values represent the average tumor volumes \pm SD of four tumors. The asterisk $\left(^{*}\right)$ in $(\mathbf{B})$ and $(\mathbf{C})$ denotes a statistical significance from ITD1 treated and DMSO treated samples determined by a two-tailed, unpaired $T$ test. D, E Representative tumors generated by DMSO- or ITD1-pretreated $p 18^{-1-}$; Brca ${ }^{\text {MGKO }}$ cells were analyzed by Western blot (D) and IHC (E). The H-scores for $p$-Smad2, Twist, and Tgf $\beta \mathrm{r} 2$ in IHC were calculated ( $\mathrm{E}$, right panel). The results represent the mean \pm SD of four individual tumors per group. Statistical significance was determined by a two-tailed, unpaired $T$ test.

Importantly, across both ER-negative and ER-positive tumors, we observed a significant inverse relationship between TGF $\beta$ R2 protein and BRCA1 mRNA levels (Figs. 7C-F, S7C). Together, these clinical findings are consistent with our results in mice, thereby suggesting an opportunity to use murine systems to further explore how BRCA1 status, TGF $\beta R 2$ signaling, and EMT intersect to control the biology of human tumors.

We examined EMT, basal-like, and CL signatures in the TCGA breast cancer dataset [3, 31, 32]. Not accounting for intrinsic subtype, BRCA1 mutant tumors showed an elevation of EMT/CLlike features as compared to BRCA1 Wt tumors (Fig. S8A), although not to the same extent as $\mathrm{CL}$ tumors. Since none of the five $\mathrm{CL}$ tumors were BRCA1 mutant, we were unable to analyze the correlation between BRCA1 mutation status and CL features in this subtype. Thus, we next limited our analysis to basal-like breast cancers, and again found a tendency for enhanced EMT/CL-like features in BRCA1 basal-like tumors, however, these differences were not statistically significant when compared to BRCA1 Wt tumors. We speculate that these observations might indicate that loss of BRCA1 leads to more EMT-like features in a proportion of cells within a tumor, but not the extent that the intrinsic subtype of the tumor bulk is significantly changed. In agreement, we observed that the basal subtype expression signature in BRCA1 mutant basal-like tumors also trended lower than BRCA1 Wt basallike tumors (Fig. S8B).

\section{DISCUSSION}

A number of studies have reported a relationship between BRCA1 and the basal-like TNBC subtype $[2,33,34]$. Here we expand on these studies by showing Brca1 alters the expression of $\mathrm{Tgf} \beta \mathrm{r} 2$ to elevate Tgf $\beta$ signaling and EMT in breast cancer cells. Targeted 
A

\begin{tabular}{|l|l|}
\hline $\begin{array}{l}\text { METABRIC } \\
(\mathrm{n}=1584)\end{array}$ & $\begin{array}{l}\text { Correlation with } \\
\text { BRCA1 Coefficient }\end{array}$ \\
\hline TGF $\beta R 1$ & $0.046(\mathrm{p}=0.069)$ \\
\hline TGF $3 R 2$ & $-0.352(\mathrm{p}=1.86 \mathrm{E}-47)$ \\
\hline
\end{tabular}

B

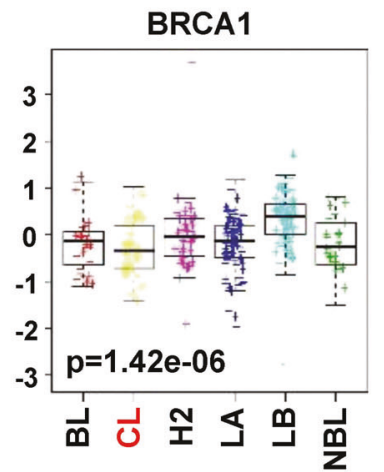

D

\begin{tabular}{|l|l|l|l|}
\hline $\begin{array}{l}\text { Case } \\
\text { no. }\end{array}$ & $\begin{array}{l}\text { TGF } \beta R 2 \\
\text { (H Score) }\end{array}$ & \\
\hline 1 & + & 80 & 1.3 \\
\hline 2 & + & 60 & 2.0 \\
\hline 3 & + & 60 & 1.7 \\
\hline 4 & + & 50 & 1.5 \\
\hline 5 & + & 40 & 1.6 \\
\hline 6 & + & 40 & 2.1 \\
\hline 7 & + & 40 & 1.5 \\
\hline 8 & + & 30 & 2.4 \\
\hline 9 & + & 20 & 2.7 \\
\hline 10 & - & 150 & 0.7 \\
\hline 11 & - & 120 & 1.2 \\
\hline 12 & - & 100 & 0.8 \\
\hline 13 & - & 90 & 1.3 \\
\hline 14 & - & 80 & 1.0 \\
\hline 15 & - & 80 & 1.5 \\
\hline 16 & - & 80 & 1.4 \\
\hline 17 & - & 60 & 1.3 \\
\hline 18 & - & 50 & 1.8 \\
\hline 19 & - & 50 & 1.9 \\
\hline
\end{tabular}

$\mathbf{F}$
C

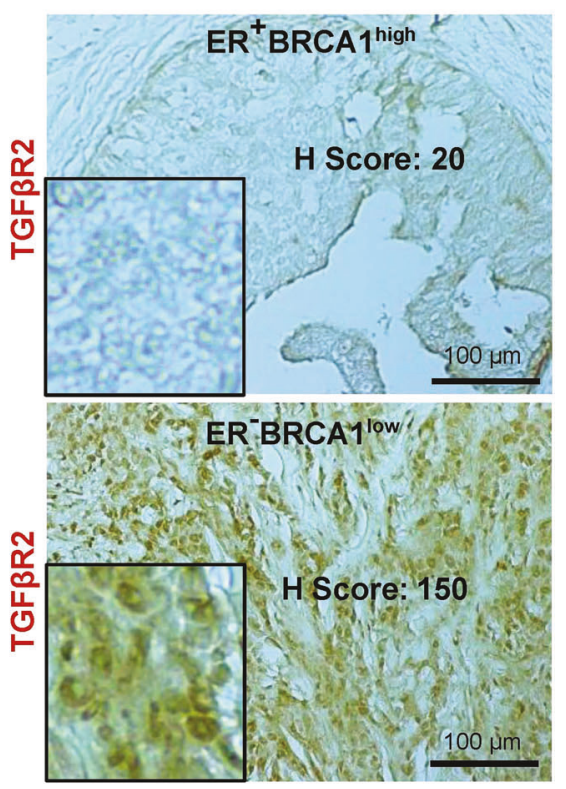

E
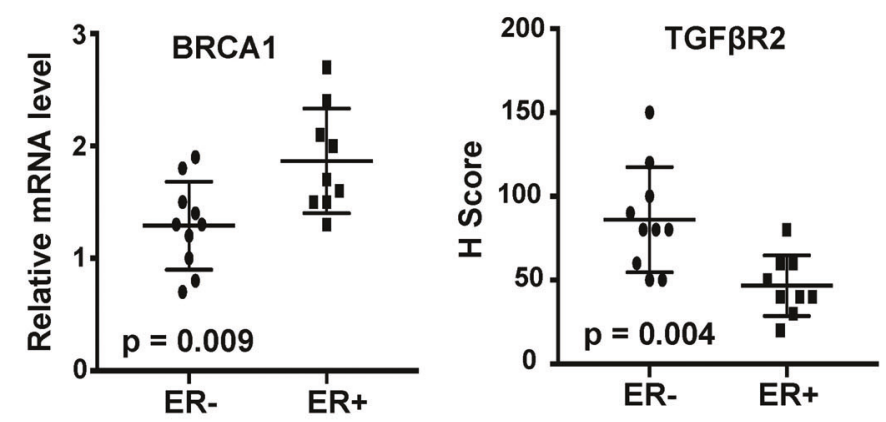

ER-
TGF $\beta$ R2

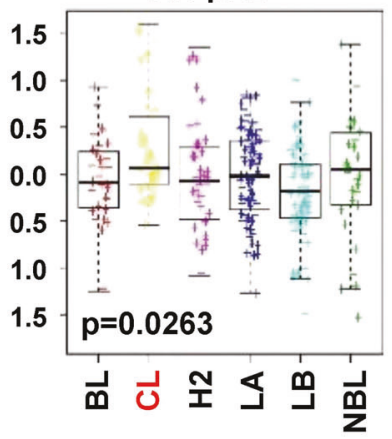

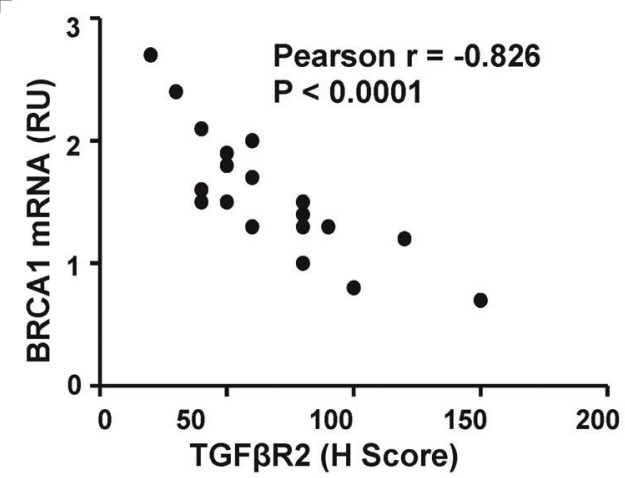

Fig. 7 BRCA1 and TGF $\beta$ R2 levels are inversely related to the $C L$ subtype of human breast cancer. A Correlation analysis of the expression of BRCA1 and TGF $\beta R 2$ for MetaBric breast cancer patients. B Analysis of gene expression in NKI295 breast cancer patients according to tumor subtype. BL basal-like, CL claudin-low, H2 Her2-enriched, LA luminal A, LB luminal B, NBL normal breast-like. C Representative immunostaining of ER positive and negative invasive human breast cancers with antibodies against TGF $\beta R 2$. D, E Summary of expression of TGF $\beta$ R2 by IHC and $B R C A 1$ by Q-RT-PCR (D). The expression levels of TGF $\beta R 2$ were quantified by $\mathrm{H}$-scores. The expression of BRCA1 was determined by Q-RT-PCR. $B R C A 1$ mRNA levels relative to that of T47D cells were determined as we previously reported [19]. Analysis of the expression of TGF $\beta R 2$ by IHC and $B R C A 1$ by Q-RT-PCR in ER + and ER-invasive breast cancers (E). Statistical significance was determined by a two-tailed, unpaired $T$ test. F Correlation analysis of BRCA1 mRNA levels and H scores of TGF $\beta$ R2 expression for breast cancer samples.

deletion of, or pharmaceutical inhibition of, Tgf $\beta \mathrm{r} 2$ in Brca1deficient tumor cells reduced EMT and suppressed tumorigenesis and metastasis. Moreover, we found BRCA1 mRNA was low and TGF $\beta R 2$ mRNA was high in the claudin-low TNBC subtype. Thus, BRCA1 function may not only be implicated in the basal-like molecular subtype but also in claudin-low as well. Importantly, this also builds upon the body of work showing a correlation between EMT and the $C L$ subtype $[4,35,36]$ by showing a mechanistic connection between BRCA1 and TGF $\beta$ signaling in an epitheliumautonomous manner.

While our study demonstrates TGF $\beta R 2$ induces malignant phenotypes in p18/BRCA1-deficient tumors, other studies show 
opposing roles in tumor suppression or tumor promotion [12, 14]. In favor of the malignant role for TGF $\beta R 2$, overexpression of TGF $\beta 22$ or upregulation of TGF $\beta$ signature genes is associated with lung metastasis as well as lower survival in human BLBCs $[16,17]$, and higher stromal TGF $\beta R 2$ is associated with poorer prognosis breast cancers [37]. Inhibition of TGF $\beta R 2$ in human or mouse breast cancer cell lines reduces metastasis and blocks chemotherapy-induced CSC expansion [14, 38]. In support of the tumor suppressor function of TGF $\beta R 2$, it has been found that in humans, reduction of or loss of TGF $\beta R 2$ is associated with an increased risk of developing high-grade carcinoma in situ and invasive breast cancer [39, 40]. In addition, loss of TGF $\beta R 2$ in stromal cancer-associated fibroblasts is linked to shortened patient survival [41]. In mouse models, the deletion of $\operatorname{Tgf} \beta \mathrm{r} 2$, or expression of dominant-negative type $\operatorname{Tgf} \beta \mathrm{r} 2$, results in or accelerates mammary tumor development and progression [14]. Collectively, these prior data and our study suggest that the role of $\mathrm{Tgf} \beta \mathrm{r} 2$ is context-dependent and possibly related to BRCA1 function/regulation.

Understanding the genomic context contributing to Tgf $\mathrm{Br} 2$ expression and function could be important for guiding therapies. In particular, our study suggests that a targetable TGF $\beta$ R signaling pathway exists in many BRCA1-deficient TNBC. Very few therapeutic options are available for ER-negative BLBCs. More than half of BLBCs have a dysfunctional BRCA1 pathway and harbor defects in DNA damage repair which make these patients initially respond well to DNA-damaging agents [2, 34, 42]. However, tumor recurrence and acquired resistance to DNAdamaging agents combine to decrease the survival of such patients $[43,44]$. In addition, most BRCA1-deficient BLBCs carry a dysfunctional INK4-RB pathway [2, 45-47]. Specifically, our combination of p18 and Brca1 loss model those tumors with INK4-RB pathway deficits. Therefore, our results might suggest a context where $\mathrm{Tgf} \beta \mathrm{r} 2$ might contribute to malignancy in human TNBC and reveal, for the first time, that a targetable TGF $\beta R$ signaling pathway is directly activated by BRCA1-deficiency in the induction of EMT in breast cancers.

While this is all very straightforward in our controlled in vitro and mouse model systems, the manifestation in human tumors is more complex. In the limited number of $\mathrm{CL}$ tumors examined, which have molecular similarities to EMT [35], patterns of BRCA1 and TGF $\beta R 2$ matched our experimental data in mouse models and human cell lines. Given that none of these tumors was BRCA1 mutant, these processes might also be epigenetically influenced. Further, our analysis of human basal-like tumors suggests that BRCA1 mutations might impact the proportion of cells with EMTlike features as there appears to be a trade-off between "basalness" and "claudin-low-ness" tracking with BRCA1 status. This may imply that additional cues are required to drive EMT in these cells, which we anticipate might include local production of TGF $\beta$; additional experimental studies will be needed to confirm this.

The above observations highlight our incomplete understanding of the mechanisms leading to EMT and claudin-low characteristics in TNBC. Yet, with the parallels between our mouse models and human tumors (and cell lines), we anticipate continued progress using this murine system to understand TNBC tumor heterogeneity. In addition to carrying a dysfunctional INK4-RB pathway, most BRCA1-deficient BLBCs harbor p53 mutations [2, 45-47]. Most studies of Brcal in mice co-mutate Brcal with one of the genes in the $p 53$ pathway [48]. However, mutation of $p 53$ alone stimulates TGF $\beta R 2$ and induces basal-like and $C L$ subtype mammary tumors $[4,49,50]$. Our results demonstrate that Brca1 suppresses TGF $\beta R 2-$ mediated EMT in mammary tumorigenesis in the context of INK-RB inactivation under a genetically intact $p 53$ background. Further, we find that some of the Brcal deficient mammary tumors are $\mathrm{CL}$ $[3,33,51]$ and that Brca1 deficiency induces basal-like mammary tumors with activation of EMT $[18,19]$, which is recently confirmed by an independent group $[52,53]$. Thus, we provide an important mouse model for specific subsets of TNBC and uncover key molecular alterations that govern tumor heterogeneity and the malignant potential of these tumor types that might be effectively managed by targeting the TGF $\beta$ pathway.

\section{MATERIALS AND METHODS}

\section{Mice, histopathology, and immunostaining}

The generation of $p 18^{-/-}, p 18^{+/-}$, and $p 18^{-1-}: \mathrm{BrCa}^{+/-}$mice in Balb/c background, and $p 18^{-/-}$and $p 18^{-/-} ; B_{r c a} 1^{f / f} ;$ MMTV-Cre $\left(p 18^{-/-}\right.$; Brca $^{M G K O}$ ) mice in Balb/c-B6 mixed background has been previously described $[18,19,54]$. The Institutional Animal Care and Use Committee at the University of Miami and Shenzhen University approved all animal procedures. Animals were housed in a specific pathogen-free environment with a 12/12 light cycle. Animals were euthanized by exposure to isoflurane followed by cervical dislocation. At least four female mice were analyzed for each genotype, or were transplanted with each type of tumor cells. Histopathology and immunohistochemistry (IHC) were performed as previously described $[18,19,54]$. The primary antibodies used were: TGF $\beta R 1, T G F \beta R 2$ (Santa Cruz), p-Smad2, p-FRA1 (Cell signaling), CK5 (Covance), and Vim (Abcam). Immunocomplexes were detected using the Vectastain $A B C D A B$ kit according to the manufacturer's instructions (Vector Laboratories). The positive results of IHC were quantified by $\mathrm{H}$ score, as previously described [55].

\section{Mammary tumor cell preparation, cell culture, tumorsphere formation assay, overexpression and knockdown of BRCA1, and TGF $\beta$ treatment}

Primary mammary tumors were dissected and cell suspensions were prepared as previously described [18, 19, 54]. T47D, HCC1937, SUM149, MDA-MB-231, and MCF7 cells were cultured per ATCC recommendations. For primary tumorsphere formation assay, mammary tumor cells were plated onto ultra-low attachment plates, in serum-free DMEM-F12, as previously described $[19,54]$. Primary tumorspheres formed were collected and counted after 10 days of culture. For the secondary tumorsphere formation assay, primary tumorspheres formed were collected and dissociated. $10^{4}$ dissociated cells were plated in triplicates with or without ITD1 (BioVision) treatment. Secondary tumorspheres that formed after 6 days of culture were counted. For ectopic expression of BRCA1, HCC1937 and SUM149 cells were transfected with pBabe-empty or pBabe-HA-BRCA1 as previously described [19]. For BRCA1 knockdown, T47D, MCF7, and MDA-MB-231 cells were infected with pGIPZ-empty (Sh-Ctrl) and pGIPZshBRCA1 (Sh-BRCA1) lentiviral vectors that were purchased from Open Biosystems, as previously described [19]. For TGF $\beta$ treatment, cells were starved in a serum-free medium for $24 \mathrm{~h}$ and then exposed to DMSO or TGF $\beta$ with an indicated period before analysis.

\section{CRISPR-mediated Tgf $\beta \mathrm{r} 2$ knockout, transplantation, and analysis of metastasis}

For CRISPR-mediated Tgf $\beta \mathrm{r} 2$ knockout in primary tumor cells, Tgf $\beta \mathrm{r} 2$ Double Nickase and control Double Nickase plasmids (Santa Cruz) were transfected into $\mathrm{p} \mathrm{8}^{-/-}$; Brcal ${ }^{M G K O}$ primary tumor cells, respectively, following the manufacturer's protocol. After selection with puromycin for 3 days, GFP-positive cells were FACS sorted for further analysis. For in vivo transplantation, primary $p 18^{-/-} ; \mathrm{BrCa}^{\mathrm{MGKO}}$ and $\mathrm{p} 18^{-/-}$or Tgf $\mathrm{Br} 2-$ and control-depleted $p 18^{-/-} ; B r c a 1^{M G K O}$ tumor cells were suspended in a $50 \%$ solution of Matrigel (BD) and then inoculated into the left and right inguinal mammary fat pads (MFPs) of 4-week-old female NSG mice (Jackson Laboratory), respectively, in a pairwise manner. Four or two weeks after transplantation, animals were euthanized and mammary tumors were analyzed. For ex vivo transplantation, primary $p 18^{-1-} ;$ Brca $^{\text {MGKO }}$ tumor cells were cultured to generate primary tumorspheres. $10^{4}$ cells dissociated from primary tumorspheres were treated with DMSO or ITD1 for 6 days. 1,000 live cells were transplanted into MFPs of NSG mice. Four weeks after transplantation, animals were euthanized and mammary tumors were analyzed. The tumor size was measured daily with a caliper. Tumor volumes were calculated as $\mathrm{V}=\mathrm{a} \times \mathrm{b}^{2} / 2$, while " $\mathrm{a}$ " is the largest diameter and " $\mathrm{b}$ " is the smallest.

For analysis of lung metastasis from mammary tumors, $p 18^{-1-}$; Brca $^{\text {MGKO }}$ tumor cells were inoculated into the MFPs of NSG mice. When newly generated tumors either reached the IACUC designated endpoint size $\left(1.3 \mathrm{~cm}^{3}\right.$; in $4-7$ weeks) or the mice became moribund, the lungs were examined for detection of metastasis. For quantification of the number of 
metastatic nodules in the lungs, fixed lung tissues of all five lobes were sagittally sectioned at $200-\mu \mathrm{m}$ intervals. At least three sections for each lobe were prepared and stained with H.E. The metastatic nodules in each lobe of lung tissue were confirmed by H.E. staining, counted under a microscope, and averaged. The number of nodules in all lobes was then calculated.

\section{Microarray analysis, western blot, and chromatin- immunoprecipitation (ChIP) assay}

RNA was extracted and purified from tumors using a RNeasy kit (Qiagen). Tumor RNA was reverse transcribed, amplified, and labeled with Cy5. Wt mammary tissue reference RNA was reverse transcribed, amplified, and labeled with Cy3. The amplified sample and reference were co-hybridized to Agilent $4 \times 180 \mathrm{k}$ custom mouse microarrays and were analyzed as previously described [51]. Gene expression data for $p 18^{-/-}, p 18^{+/-}$, and p $18^{-1-}:$ Brca $1^{+/-}$tumors was uploaded to the UNC microarray database. The Log(base2) of R/G Lowess Normalized Ratio (Mean) was taken for each array. For each channel, Lowess Normalized Net (Mean) greater than or equal to 10 was used to determine the presence of a signal. Genes present across $70 \%$ of samples were maintained and the remaining missing values were calculated and replaced using KNN imputation. Next genes were median centered and samples were standardized for the working gene matrix. Gene set enrichment analysis (GSEA) was performed using the GenePattern server $[56,57]$. The gene signatures for Tgf $\beta$ and NF-KB signaling activities and EMT were published $[35,58,59]$. Gene expression data of mammary tumors coming from p1 $18^{-1-}, p 18^{+/-}$, and $p 18^{-1-} ;$ Brca $^{+/-}$mice were deposited on the Gene Expression Omnibus under accession GSE155239. Data were obtained using Agilent microarrays as published [60]. Data were combined with a published dataset containing $\mathrm{K} 14-\mathrm{Cre} ; \mathrm{p} 3^{\mathrm{f} / \mathrm{f}} ; \mathrm{Brca}^{\mathrm{f} / \mathrm{f}}$ mouse mammary tumors as well as additional intrinsically credentialed genetically engineered mouse models (GEMMs) using the UNC Microarray database [33]. Intensity values were lowess normalized and relative counts established using median centering.

For the western blot, tissue and cell lysates were prepared as previously reported $[19,54]$. The primary antibodies used were: BRCA1 and TGF $\beta R 2$, (Santa Cruz), Vimentin, E-cad, Snail, Twist, p-Fra1, p-Smad2, p-Erk, p-Jnk, p-Akt (Cell signaling), and Gapdh (Ambion). All blots were derived from the same experiment and were processed in parallel. ChIP assays were carried out as previously described $[19,54]$. Briefly, cells were treated with $1.5 \%$ formaldehyde and sonicated. Anti-BRCA1 antibody (D-9, Santa Cruz) or control mouse IgG was used to precipitate chromatin associated with BRCA1. Q-PCR was performed to determine the relative abundance of target DNA. Specific primers for the analysis of BRCA1 binding to TGF $\beta 22$ are listed in Table. S1.

\section{Dual-luciferase reporter assay}

The human TGF $\beta$ R2 promoter region -2589 to -1613 that covers P5 and part of P4 primers used for ChIP analysis and contains a GATA3/BRCA1 binding site with consensus sequences, TGATTG, at -2115 was inserted into the pGL3-basic (Promega), as pGL3-TGFßR2-WT. With pGL3-TGFBR2-WT as a template, GATA3 binding site TGATTG was mutated into TACTTG to generate pGL3-TGF $\beta$ R2-Mut by site-directed mutagenesis. Renilla plasmid was a gift from S. Y. Fuchs (University of Pennsylvania). For the TGF $\beta$ R2 promoter-luciferase reporter assay, T47D-sh-Ctrl, T47D-sh-BRCA1, and SUM149 cells were seeded in a 24-well plate. T47D-sh-Ctrl and T47D-shBRCA1 cells were transfected with Renilla and either pGL3-TGFßR2-WT or pGL3-TGFBR2-Mut. SUM149 cells were transfected with Renilla plus pGL3TGFBR2-WT or pGL3-TGFßR2-Mut, as well as pBabe-empty or pBabe-HABRCA1. The transfection efficiency was monitored using the Renilla vector as an internal control. Two days after transfection, cell lysates were collected and subjected to luciferase assay using the Dual-Luciferase Reporter Assay System (Promega). Two independent transfection experiments were conducted, and each luciferase assay was performed in triplicates. Normalized data was calculated as the ratio of the firefly/Renilla luciferase activities.

\section{Human tumor samples and gene-expression data sets}

Formalin-fixed paraffin-embedded (FFPE) human breast cancer samples lacking patient-identifying information were obtained from the Tissue Bank Core Facility at the University of Miami and the Department of Pathology at Shenzhen University. Samples used for this study consisted of non-treated invasive breast carcinomas with known ER status. Tumor samples were microdissected. Samples with tumor cell content $>75 \%$ were used for RNA extraction. The expression of BRCA1 was determined by Q-RT$\mathrm{PCR}$, as previously reported [19]. Pearson correlation coefficient and $P$ value (two-tailed) of BRCA1 mRNA levels and $H$ scores of TGF $\beta R 2$ expression for breast cancer samples were calculated by GraphPad Prism software. The correlation of expression of TGF $\beta R 1 / 2$ mRNA with BRCA1 mRNA was analyzed with NKI295 [29], MetaBric [30], and UNC337 [3] human breast cancer datasets. The NKI295 dataset was analyzed to compare gene expression versus six breast cancer subtypes using a twoway analysis of variance (ANOVA).

\section{Statistical analysis}

All data are presented as the mean \pm SD for at least three repeated individual experiments for each group. Quantitative results were analyzed by two tailed Fisher Exact test or two-tailed Student's $t$-test. $P<0.05$ was considered statistically significant.

Pearson correlation coefficient of BRCA1 and TGF $\beta R 2$ expression was calculated by GraphPad Prism software. The NKI295 dataset was analyzed to compare gene expression versus six breast cancer subtypes using a twoway analysis of variance (ANOVA).

\section{DATA AVAILABILITY}

Murine tumor gene expression data was deposited at the Gene Expression Omnibus under accession number GSE155239. All other datasets can be found as part of this manuscript.

\section{REFERENCES}

1. Althuis MD, Fergenbaum JH, Garcia-Closas M, Brinton LA, Madigan MP, Sherman ME. Etiology of hormone receptor-defined breast cancer: a systematic review of the literature. Cancer Epidemiol Biomark Prev. 2004;13:1558-68.

2. Koboldt DC, Fulton RS, McLellan MD, Schmidt H, Kalicki-Veizer J, McMichael JF, et al. Comprehensive molecular portraits of human breast tumours. Nature 2012;487:330-7.

3. Prat A, Parker JS, Karginova O, Fan C, Livasy C, Herschkowitz Jl, et al. Phenotypic and molecular characterization of the claudin-low intrinsic subtype of breast cancer. Breast Cancer Res. 2010;12:R68.

4. Herschkowitz Jl, Zhao W, Zhang M, Usary J, Murrow G, Edwards D, et al. Comparative oncogenomics identifies breast tumors enriched in functional tumorinitiating cells. Proc Natl Acad Sci USA. 2012;109:2778-83.

5. Wright MH, Calcagno AM, Salcido CD, Carlson MD, Ambudkar SV, Varticovski L. Brca1 breast tumors contain distinct CD44+/CD24- and CD133+ cells with cancer stem cell characteristics. Breast Cancer Res. 2008;10:R10.

6. Wicha MS. Cancer stem cell heterogeneity in hereditary breast cancer. Breast Cancer Res. 2008;10:105.

7. Ye X, Weinberg RA, Epithelial-Mesenchymal. Plasticity: A Central Regulator of Cancer Progression. Trends cell Biol. 2015;25:675-86.

8. Mani SA, Guo W, Liao MJ, Eaton EN, Ayyanan A, Zhou AY, et al. The epithelialmesenchymal transition generates cells with properties of stem cells. Cell 2008:133:704-15.

9. Kalluri R, Weinberg RA. The basics of epithelial-mesenchymal transition. J Clin Invest. 2009;119:1420-8.

10. Ye X, Tam WL, Shibue T, Kaygusuz Y, Reinhardt F, Ng Eaton E, et al. Distinct EMT programs control normal mammary stem cells and tumour-initiating cells. Nature 2015;525:256-60.

11. Scheel C, Eaton EN, Li SH, Chaffer CL, Reinhardt F, Kah KJ, et al. Paracrine and autocrine signals induce and maintain mesenchymal and stem cell states in the breast. Cell 2011;145:926-40.

12. Moses $\mathrm{H}$, Barcellos-Hoff MH. TGF-beta biology in mammary development and breast cancer. Cold Spring Harb Perspect Biol. 2011;3:a003277.

13. Derynck R, Muthusamy BP, Saeteurn KY. Signaling pathway cooperation in TGFbeta-induced epithelial-mesenchymal transition. Curr Opin Cell Biol. 2014;31: 56-66.

14. Tan AR, Alexe G, Reiss M. Transforming growth factor-beta signaling: emerging stem cell target in metastatic breast cancer? Breast Cancer Res Treat. 2009;115: 453-95.

15. Shipitsin M, Campbell LL, Argani P, Weremowicz S, Bloushtain-Qimron N, Yao J, et al. Molecular definition of breast tumor heterogeneity. Cancer Cell. 2007;11: 259-73.

16. Buck MB, Fritz P, Dippon J, Zugmaier G, Knabbe C. Prognostic significance of transforming growth factor beta receptor II in estrogen receptor-negative breast cancer patients. Clin Cancer Res. 2004;10:491-8. 
17. Padua D, Zhang XH, Wang Q, Nadal C, Gerald WL, Gomis RR, et al. TGFbeta primes breast tumors for lung metastasis seeding through angiopoietin-like 4. Cell 2008;133:66-77.

18. Bai F, Smith MD, Chan HL, Pei XH. Germline mutation of Brca1 alters the fate of mammary luminal cells and causes luminal-to-basal mammary tumor transformation. Oncogene 2013;32:2715-25.

19. Bai F, Chan HL, Scott A, Smith MD, Fan C, Herschkowitz Jl, et al. BRCA1 Suppresses Epithelial-to-Mesenchymal Transition and Stem Cell Dedifferentiation during Mammary and Tumor Development. Cancer Res. 2014;74:6161-72.

20. Scott A, Bai F, Chan HL, Liu S, Ma J, Slingerland JM, et al. p16INK4a suppresses BRCA1-deficient mammary tumorigenesis. Oncotarget 2016;7:84496-507.

21. Sedic $M$, Skibinski A, Brown N, Gallardo $M$, Mulligan $P$, Martinez $P$, et al. Haploinsufficiency for BRCA1 leads to cell-type-specific genomic instability and premature senescence. Nat Commun. 2015;6:7505.

22. Bai $F$, Zhang LH, Liu X, Wang C, Zheng C, Sun J, et al. GATA3 functions downstream of BRCA1 to suppress EMT in breast cancer. Theranostics 2021;11: 8218-33.

23. Mao R, Fan Y, Mou Y, Zhang H, Fu S, Yang J. TAK1 lysine 158 is required for TGFbeta-induced TRAF6-mediated Smad-independent IKK/NF-kappaB and JNK/AP-1 activation. Cell Signal. 2011;23:222-7.

24. Sakurai H, Shigemori N, Hasegawa K, Sugita T. TGF-beta-activated kinase 1 stimulates NF-kappa B activation by an NF-kappa B-inducing kinase-independent mechanism. Biochem Biophys Res Commun. 1998;243:545-9.

25. Andrechek ER, Cardiff RD, Chang JT, Gatza ML, Acharya CR, Potti A, et al. Genetic heterogeneity of Myc-induced mammary tumors reflecting diverse phenotypes including metastatic potential. Proc Natl Acad Sci USA. 2009;106:16387-92.

26. Wang C, Bai F, Zhang LH, Scott A, Li E, Pei XH. Estrogen promotes estrogen receptor negative BRCA1-deficient tumor initiation and progression. Breast Cancer Res. 2018;20:74.

27. Tkocz D, Crawford NT, Buckley NE, Berry FB, Kennedy RD, Gorski JJ, et al. BRCA1 and GATA3 corepress FOXC1 to inhibit the pathogenesis of basal-like breast cancers. Oncogene. 2011;31:3667-78.

28. Willems E, Cabral-Teixeira J, Schade D, Cai W, Reeves P, Bushway PJ, et al. Small molecule-mediated TGF-beta type II receptor degradation promotes cardiomyogenesis in embryonic stem cells. Cell Stem Cell. 2012;11:242-52.

29. van de Vijver MJ, He YD, van't Veer LJ, Dai H, Hart AA, Voskuil DW, et al. A geneexpression signature as a predictor of survival in breast cancer. N. Engl J Med. 2002;347:1999-2009.

30. Curtis C, Shah SP, Chin SF, Turashvili G, Rueda OM, Dunning MJ, et al. The genomic and transcriptomic architecture of 2,000 breast tumours reveals novel subgroups. Nature 2012;486:346-52.

31. Parker JS, Mullins $M$, Cheang MC, Leung $S$, Voduc D, Vickery $T$, et al. Supervised risk predictor of breast cancer based on intrinsic subtypes. J Clin Oncol. 2009;27:1160-7.

32. Taube JH, Herschkowitz Jl, Komurov K, Zhou AY, Gupta S, Yang J, et al. Core epithelial-to-mesenchymal transition interactome gene-expression signature is associated with claudin-low and metaplastic breast cancer subtypes. Proc Natl Acad Sci USA. 2010;107:15449-54.

33. Hollern DP, Contreras CM, Dance-Barnes S, Silva GO, Pfefferle AD, Xiong J, et al. A mouse model featuring tissue-specific deletion of p53 and Brca1 gives rise to mammary tumors with genomic and transcriptomic similarities to human basallike breast cancer. Breast Cancer Res Treat. 2019;174:143-55.

34. Zhu X, Shan L, Wang F, Wang J, Wang F, Shen G, et al. Hypermethylation of BRCA1 gene: implication for prognostic biomarker and therapeutic target in sporadic primary triple-negative breast cancer. Breast Cancer Res Treat. 2015;150:479-86.

35. Hollern DP, Swiatnicki MR, Andrechek ER. Histological subtypes of mouse mammary tumors reveal conserved relationships to human cancers. PLoS Genet. 2018;14:e1007135.

36. Hennessy BT, Gonzalez-Angulo AM, Stemke-Hale K, Gilcrease MZ, Krishnamurthy $S$, Lee JS, et al. Characterization of a naturally occurring breast cancer subset enriched in epithelial-to-mesenchymal transition and stem cell characteristics. Cancer Res. 2009;69:4116-24.

37. Barlow J, Yandell D, Weaver D, Casey T, Plaut K. Higher stromal expression of transforming growth factor-beta type II receptors is associated with poorer prognosis breast tumors. Breast Cancer Res Treat. 2003;79:149-59.

38. Bhola NE, Balko JM, Dugger TC, Kuba MG, Sanchez V, Sanders M, et al. TGF-beta inhibition enhances chemotherapy action against triple-negative breast cancer. J Clin Invest. 2013;123:1348-58.

39. Gobbi H, Dupont WD, Simpson JF, Plummer WD Jr., Schuyler PA, Olson SJ, et al. Transforming growth factor-beta and breast cancer risk in women with mammary epithelial hyperplasia. J Natl Cancer Inst. 1999;91:2096-101.

40. Gobbi H, Arteaga CL, Jensen RA, Simpson JF, Dupont WD, Olson SJ, et al. Loss of expression of transforming growth factor beta type II receptor correlates with high tumour grade in human breast in-situ and invasive carcinomas. Histopathology 2000;36:168-77.
41. Busch S, Acar A, Magnusson Y, Gregersson P, Ryden L, Landberg G. TGF-beta receptor type-2 expression in cancer-associated fibroblasts regulates breast cancer cell growth and survival and is a prognostic marker in pre-menopausal breast cancer. Oncogene 2015;34:27-38.

42. De Summa S, Pinto R, Sambiasi D, Petriella D, Paradiso V, Paradiso A, et al. BRCAness: a deeper insight into basal-like breast tumors. Ann Oncol. 2013;24: viii13-viii21.

43. Lord CJ, Tutt AN, Ashworth A. Synthetic lethality and cancer therapy: lessons learned from the development of PARP inhibitors. Annu Rev Med. 2015;66:455-70.

44. Maxwell KN, Domchek SM. Cancer treatment according to BRCA1 and BRCA2 mutations. Nat Rev Clin Oncol. 2012;9:520-8.

45. Jonsson G, Staaf J, Vallon-Christersson J, Ringner M, Gruvberger-Saal SK, Saal LH, et al. The retinoblastoma gene undergoes rearrangements in BRCA1-deficient basal-like breast cancer. Cancer Res. 2012;72:4028-36.

46. Stefansson OA, Jonasson JG, Olafsdottir K, Hilmarsdottir H, Olafsdottir G, Esteller $\mathrm{M}$, et al. CpG island hypermethylation of BRCA1 and loss of pRb as co-occurring events in basal/triple-negative breast cancer. Epigenetics 2011;6:638-49.

47. Herschkowitz Jl, He X, Fan C, Perou CM. The functional loss of the retinoblastoma tumour suppressor is a common event in basal-like and luminal B breast carcinomas. Breast Cancer Res. 2008;10:R75.

48. Drost RM, Jonkers J. Preclinical mouse models for BRCA1-associated breast cancer. Br J Cancer. 2009;101:1651-7.

49. Jiang Z, Deng $\mathrm{T}$, Jones $\mathrm{R}$, $\mathrm{Li} \mathrm{H}$, Herschkowitz Jl, Liu JC, et al. Rb deletion in mouse mammary progenitors induces luminal-B or basal-like/EMT tumor subtypes depending on p53 status. J Clin Invest. 2010;120:3296-309.

50. Chang $\mathrm{CJ}$, Chao CH, Xia W, Yang JY, Xiong Y, Li CW, et al. p53 regulates epithelialmesenchymal transition and stem cell properties through modulating miRNAs. Nat Cell Biol. 2011;13:317-23.

51. Herschkowitz JI, Simin K, Weigman VJ, Mikaelian I, Usary J, Hu Z, et al. Identification of conserved gene expression features between murine mammary carcinoma models and human breast tumors. Genome Biol. 2007;8:R76.

52. Wang H, Bierie B, Li AG, Pathania S, Toomire K, Dimitrov SD, et al. BRCA1/ FANCD2/BRG1-Driven DNA Repair Stabilizes the Differentiation State of Human Mammary Epithelial Cells. Mol Cell. 2016;63:277-92.

53. Wang $H$, Xiang D, Liu B, He A, Randle HJ, Zhang KX, et al. Inadequate DNA Damage Repair Promotes Mammary Transdifferentiation, Leading to BRCA1 Breast. Cancer Cell 2019;178:135-51 e19.

54. Pei XH, Bai F, Smith MD, Usary J, Fan C, Pai SY, et al. CDK inhibitor p18(INK4C) is a downstream target of GATA3 and restrains mammary luminal progenitor cell proliferation and tumorigenesis. Cancer Cell. 2009;15:389-401.

55. Goulding H, Pinder S, Cannon P, Pearson D, Nicholson R, Snead D, et al. A new immunohistochemical antibody for the assessment of estrogen receptor status on routine formalin-fixed tissue samples. Hum Pathol. 1995;26:291-4.

56. Reich M, Liefeld T, Gould J, Lerner J, Tamayo P, Mesirov JP. GenePattern 2.0. Nat Genet. 2006;38:500-1.

57. Subramanian A, Tamayo P, Mootha VK, Mukherjee S, Ebert BL, Gillette MA, et al. Gene set enrichment analysis: a knowledge-based approach for interpreting genome-wide expression profiles. Proc Natl Acad Sci USA. 2005;102:15545-50.

58. Verrecchia F, Chu ML, Mauviel A. Identification of novel TGF-beta /Smad gene targets in dermal fibroblasts using a combined cDNA microarray/promoter transactivation approach. J Biol Chem. 2001;276:17058-62.

59. Schon M, Wienrich BG, Kneitz S, Sennefelder H, Amschler K, Vohringer V, et al. KINK-1, a novel small-molecule inhibitor of IKKbeta, and the susceptibility of melanoma cells to antitumoral treatment. J Natl Cancer Inst. 2008;100:862-75.

60. Bai F, Liu S, Liu X, Hollern DP, Scott A, Wang C, et al. PDGFRbeta is an essential therapeutic target for BRCA1-deficient mammary tumors. Breast Cancer Res. 2021;23:10.

\section{ACKNOWLEDGEMENTS}

We thank Drs. Beverly Koller, Chuxia Deng, and Lothar Hennighausen for Brca1 mutant and MMTV-cre mice, Yue Xiong for discussion, Charles M. Perou for microarray analysis and discussion, Emely Pimentel and Alexandria Scott for technical support, the FACS core facility at University of Miami and Shenzhen University for cell sorting, the DVR core facility for animal husbandry. Chuying Wang thanks Xi'an Jiaotong University for financial support. This study was supported by the Guangdong Provincial Science and Technology Program (2019B030301009), National Natural Science Foundation of China (81972637), High-level university phase 2 construction funding from Shenzhen University (86000000210), Natural Science Foundation of Shenzhen City (JCYJ20190808115603580 and JCYJ20190808165803558), Natural Science Foundation of Guangdong Province (2019A1515011343 and 2021A1515011145), and the Bankhead-Coley Cancer Research grant (TBC07). 


\section{AUTHOR CONTRIBUTIONS}

$\mathrm{FB}$ and $\mathrm{XHP}$ designed the research studies. FB, CW, XL, SL, CL, SR, and XHP conducted experiments and analyzed data. $\mathrm{DH}, \mathrm{CF}$, and $\mathrm{JIH}$ carried out microarray analysis and breast cancer dataset analysis. WGZ provided technical and material support. $\mathrm{FB}, \mathrm{DH}$, and XHP wrote the manuscript. XHP supervised the project. All authors made comments on the manuscript.

\section{COMPETING INTERESTS}

The authors declare no competing interests.

\section{ETHICS STATEMENT}

The Institutional Animal Care and Use Committee at the University of Miami and Shenzhen University approved all animal procedures.

\section{ADDITIONAL INFORMATION}

Supplementary information The online version contains supplementary material available at https://doi.org/10.1038/s41419-022-04646-7.

Correspondence and requests for materials should be addressed to Xin-Hai Pei.
Reprints and permission information is available at http://www.nature.com/ reprints

Publisher's note Springer Nature remains neutral with regard to jurisdictional claims in published maps and institutional affiliations.
Open Access This article is licensed under a Creative Commons Attribution 4.0 International License, which permits use, sharing, adaptation, distribution and reproduction in any medium or format, as long as you give appropriate credit to the original author(s) and the source, provide a link to the Creative Commons license, and indicate if changes were made. The images or other third party material in this article are included in the article's Creative Commons license, unless indicated otherwise in a credit line to the material. If material is not included in the article's Creative Commons license and your intended use is not permitted by statutory regulation or exceeds the permitted use, you will need to obtain permission directly from the copyright holder. To view a copy of this license, visit http://creativecommons. org/licenses/by/4.0/.

(c) The Author(s) 2022 